ORNL/TM-2002/256

\title{
STRATEGIC PLAN FOR COORDINATING RURAL INTELLIGENT TRANSPORTATION SYSTEM (ITS) \\ TRANSIT DEVELOPMENT IN THE GREAT SMOKY MOUNTAINS NATIONAL PARK
}

\author{
L. F. Truett (TRUETTLF@ORNL.GOV) \\ S. M. Chin (CHINS@ ORNL.GOV) \\ E. C. P. Chang (ECC2005@ORNL.GOV)
}

November 2002

\author{
Prepared for the \\ FEDERAL TRANSIT ADMINISTRATION \\ U.S. DEPARTMENT OF TRANSPORTATION \\ Washington, D.C. 20590
}

Prepared by the

Center for Transportation Analysis

OAK RIDGE NATIONAL LABORATORY

Oak Ridge, Tennessee 37831-6073

managed by

UT-BATTELLE, LLC

for the

U.S. DEPARTMENT OF ENERGY

under Contract No. DE-AC05-00OR22725 


\section{STRATEGIC PLAN FOR COORDINATING RURAL INTELLIGENT TRANSPORTATION SYSTEM (ITS) TRANSIT DEVELOPMENT IN THE GREAT SMOKY MOUNTAINS NATIONAL PARK}

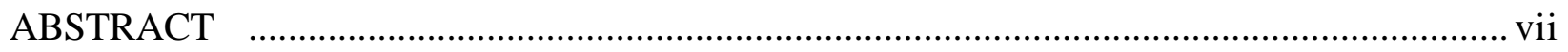

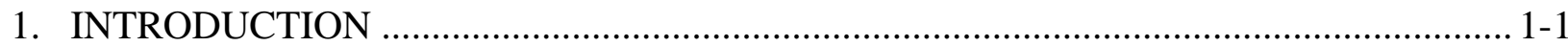

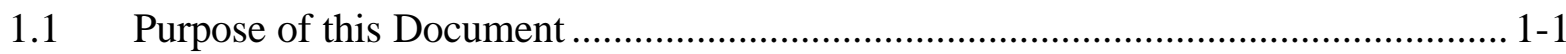

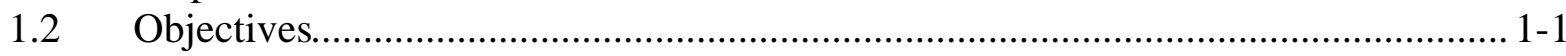

2. THE SMOKIES - AN OVERVIEW ………………....................................................

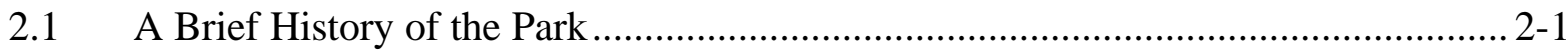

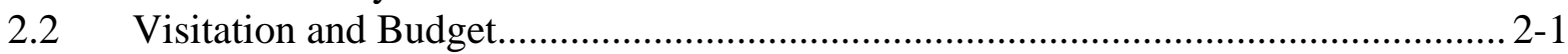

2.3 Geographical Perspective and Gateway Communities ............................................ 2-4

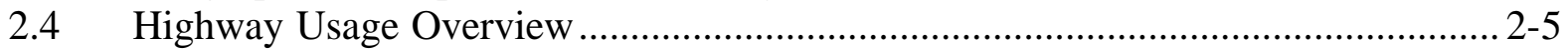

2.4.1 Cades Cove and Western Accesses............................................................... 2-6

2.4.2 Central Accesses Across the Mountain Between Tennessee and North Carolina..................................................................................... 2-6

2.4.3 Eastern Accesses .............................................................................. 2-7

$2.5 \quad$ Issues and Problems ………………………............................................... 2-8

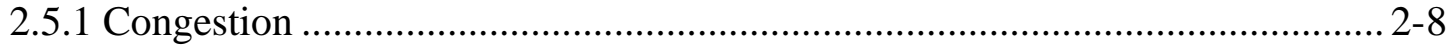

2.5.2 Environmental Degradation and Air Quality ................................................. 2-8

2.5.3 Safety .......................................................................................... 2-10

2.5.4 Visitor Experience..................................................................................... 2-11

2.6 Brief Description of Benefit and Synergy Through Cooperation ............................. 2-11

3. POTENTIAL TRANSIT INTELLIGENT TRANSPORTATION SYSTEM

TECHNOLOGIES WITHIN AND/OR NEAR THE PARK ……....................................... 3-1

3.1 ITS Technologies for Transit .........................................................................

3.2 County-Based Demand-Response-Only Transit Services ......................................... 3-2

3.3 Fixed-Route Trolley Systems ………………….......................................... 3-2

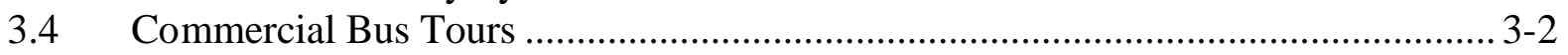

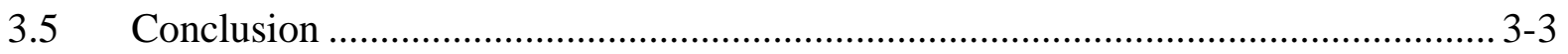

4. MASS TRANSIT SERVICES AROUND THE GREAT SMOKY MOUNTAINS

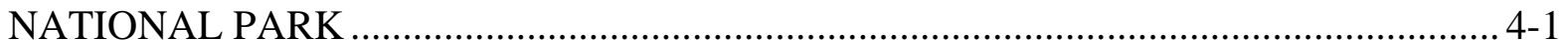

4.1 Mass Transit Services in Tennessee...................................................................... 4-1

4.1.1 East Tennessee Human Resource Agency (ETHRA) ........................................ 4-1

4.1.2 Pigeon Forge Fun Time Trolleys .................................................................... 4-2

4.1.3 Gatlinburg Mass Transit System.................................................................... 4-2

4.2 Mass Transit Services in North Carolina ………................................................ 4-4

4.2.1 Swain County ..................................................................................... $4-4$

4.2.2 Haywood County ……………………………………............................... 4-4

4.3 Harrah's Cherokee Casino Bus ............................................................................... 4-4 
4.4 Contact Information for Transit Agencies Serving the Gateway

Communities Around the GSMNP

5. PARTICIPANTS AND INTERESTED PARTIES .................................................... 5-1

5.1 Federal Agencies and Other National Organizations .......................................... 5-1

5.1.1 Department of Interior ..................................................................... 5-1

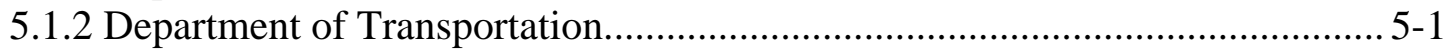

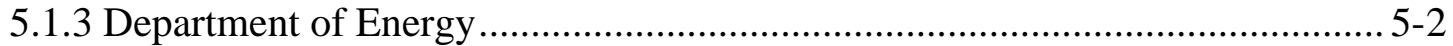

5.1.4 Tennessee Valley Authority ............................................................... 5-3

5.1.5 Environmental Protection Agency .......................................................... 5-3

5.1.6 National Parks Conservation Association.................................................. 5-4

5.1.7 National Trust for Historic Preservation......................................................... 5-5

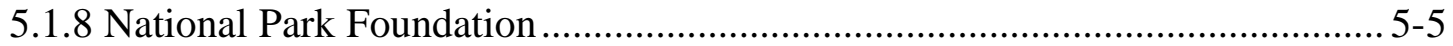

5.1.9 Appalachian Trail Conference ................................................................. 5-5

5.2 State Agencies in Tennessee and North Carolina .............................................. 5-5

5.2.1 Tennessee Department of Transportation ................................................ 5-5

5.2.2 Tennessee Department of Tourist Development............................................5-7

5.2.3 Tennessee Department of Environment and Conservation...............................5-7

5.2.4 Tennessee Historical Commission ............................................................ 5-8

5.2.5 East Tennessee Human Resource Agency ................................................. 5-8

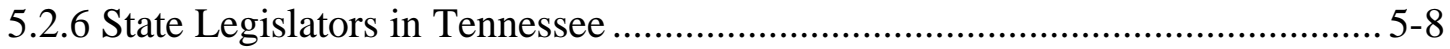

5.2.7 North Carolina Department of Transportation..............................................5-9

5.2.8 North Carolina Division of Tourism, Film and Sports Development ............. 5-10

5.2.9 North Carolina Department of Environment and Natural Resources .............5-10

5.2.10 North Carolina State Historical Preservation Office..................................... 5-10

5.2.11 State Legislators in North Carolina ............................................................ 5-10

5.3 Regional Agencies and Gateway Communities................................................5-11

5.3.1 Knoxville Regional Transportation Planning Organization........................... 5-11

5.3.2 Nine Counties/One Vision ...................................................................... 5-12

5.3.3 Highway Patrol and Incident Response Agencies ..................................... 5-12

5.3.4 County and Community Planning Commissions, Elected Officials, Chambers of Commerce, Departments of Tourism, and Visitors Bureaus..... 5-12

5.3.5 Eastern Band of the Cherokee Nation...................................................... 5-13

5.3.6 East Tennessee Economic Development Agency..................................... 5-13

5.3.7 Land of Sky Regional Council................................................................... 5-13

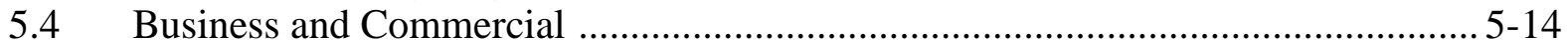

5.4.1 Transit Operators and Providers .............................................................. 5-14

5.4.2 Tourist Attractions ......................................................................... 5-14

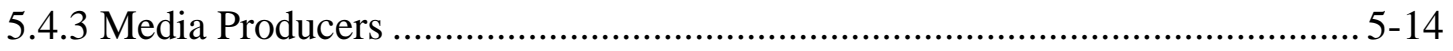

5.4.4 Other Business and Commercial Interests .............................................. 5-14

5.5 Community Interest/Political Action Groups ............................................. 5-15

5.5.1 Southern Appalachian Mountain Initiative .................................................. 5-15

5.5.2 Friends of the Great Smoky Mountains National Park .................................. 5-15

5.5.3 Great Smoky Mountains Natural History Association ................................ 5-15

5.5.4 Foothills Land Conservancy ............................................................. 5-15

5.5.5 Cades Cove Preservation Association........................................................ 5-15

Coordination of Transit Concepts in GSMNP page iv, 11/12/02 


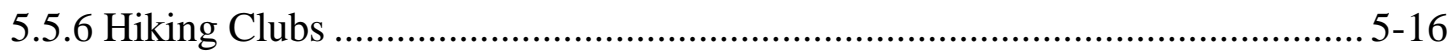

5.5.7 Horseback Riders ................................................................................ 5-16

5.5.8 Bicycling, Hiking, Camping, and Fishing Interests …………………........... 5-17

5.5.9 Mountain Air Quality Coalition.................................................................... 5-17

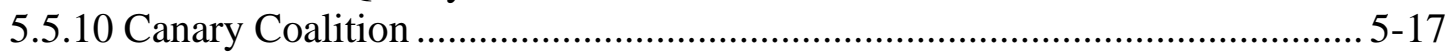

5.5.11 Western North Carolina Tomorrow …………………................................. 5-17

5.5.12 Visibility Improvement State and Tribal Association of the Southeast........ 5-18

6. STRATEGIC APPROACHES FOR A SMOKIES SOLUTION …….................................... 6-1

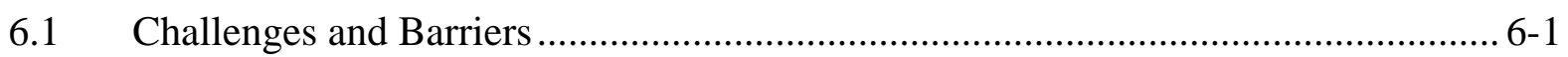

6.1.1 Infrastructure Limitations .......................................................................... 6-1

6.1.2 Environmental Concerns ............................................................................ 6-1

6.1.3 Political Issues Involving Coordination.......................................................... 6-2

6.1.4 Financial Issues .................................................................................... 6-3

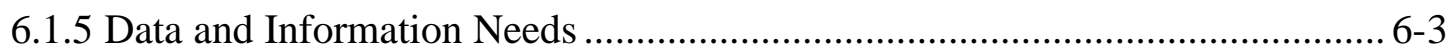

6.1.6 Technology Limitations …………………………....................................... 6-4

6.1.7 Policy Issues....................................................................................... 6-4

6.1.8 Population Concentration........................................................................... 6-5

6.2 Benefits from Use of Rural ITS Transit ......................................................... 6-5

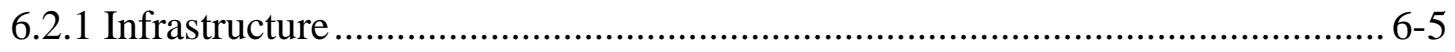

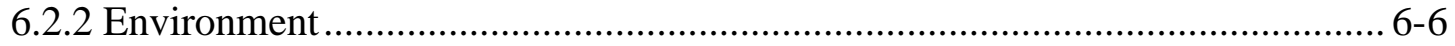

6.2.3 Political Issues........................................................................................ 6-6

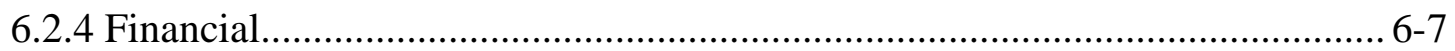

6.2.5 Data and Information ................................................................................ 6-7

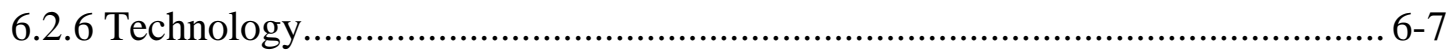

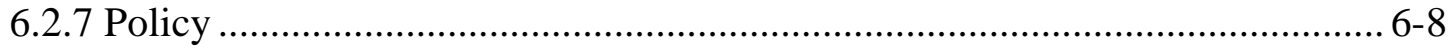

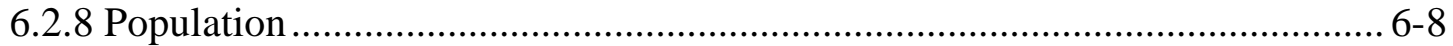

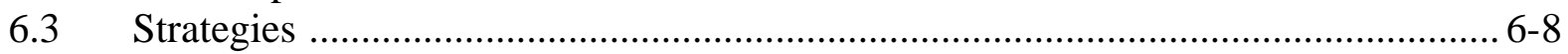

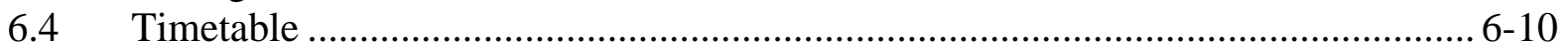

7. SUMMARY, CONCLUSIONS, AND RECOMMENDATIONS ......................................

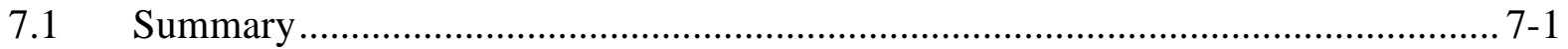

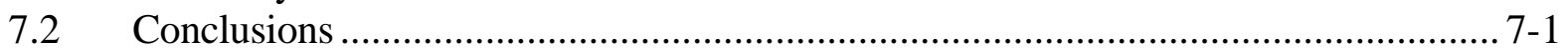

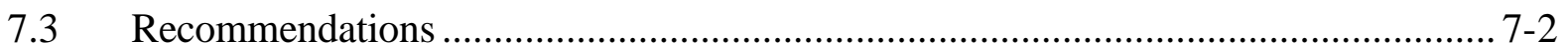

7.3.1 Coordination.............................................................................................

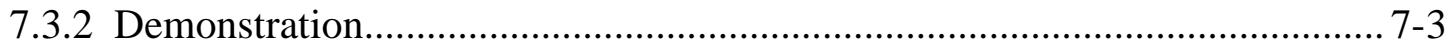

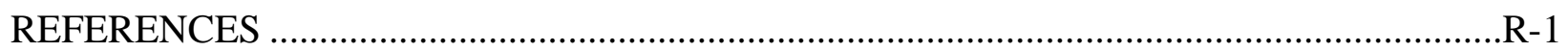

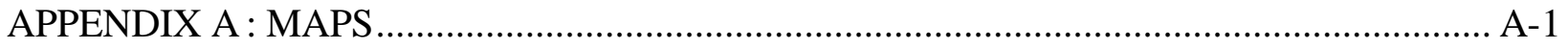

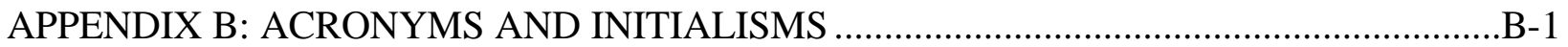

Coordination of Transit Concepts in GSMNP page v, 11/12/02 


\section{LIST OF FIGURES AND TABLES}

$\underline{\text { Figure }}$

$\underline{\text { Page }}$

2.1 Number of Vehicles Entering GSMNP

2.2 Number of Annual Visits to Selected National Parks .................................................... 2-2

2.3 Total Visits to National Parks During Calendar Year 2000 ............................................. 2-3

2.4 Federal Funding for National Parks During Fiscal Year 2000.......................................2-4

2.5 Changes in Elevation Along Border Between Tennessee and North Carolina ................... 2-8

2.6 Monitoring Locations for Parks with Highest Concentrations of Average $4^{\text {th }}$-Highest

Daily Maximum 8-hr Ozone Concentrations, 1997-1999 ............................................. 2-10

4.1 ETHRA Service Area.

4.2 National Park Trolley Route Provided by the Gatlinburg Mass Transit System

4.3 Origin Points for the Harrah's Cherokee Casino Bus

5.1 Pollutants That Contributed to Reduced Visibility on the Worst Days in 1997

$\underline{\text { Table }}$

2.1 Gateway Communities to the Smokies $2-5$ 


\begin{abstract}
The Great Smoky Mountains National Park, located along the border between North Carolina and Tennessee, is the most visited national park in the United States. This rugged, mountainous area presents many transportation challenges. The immense popularity of the Smokies and the fact that the primary mode of transportation within the park is the personal vehicle have resulted in congestion, damage to the environment, impacts on safety, and a degraded visitor experience.

Access to some of the Smokies' historical, cultural, and recreational attractions via a mass transit system could alleviate many of the transportation issues. Although quite a few organizations are proponents of a mass transit system for the Smokies, there is a lack of coordination among all parties. In addition, many local residents are not completely comfortable with the idea of transit in the Smokies.

This document provides a brief overview of the current transportation needs and limitations in the Great Smoky Mountains National Park, identifies agencies and groups with particular interests in the Smokies, and offers insights into the benefits of using Intelligent Transportation Systems (ITS) technologies in the Smokies. Recommendations for the use of rural ITS transit to solve two major transportation issues are presented.
\end{abstract}




\section{INTRODUCTION}

The Great Smoky Mountains National Park (GSMNP) is the most visited National Park in the United States. Located in both North Carolina and Tennessee, the GSMNP encompasses 800 square miles. Its proximity to major East Coast metropolitan areas; its rich cultural, historic, and environmental appeal; and its immense recreational possibilities are reasons why it is visited by about 9.5 million people each year. The mission of the National Park Service (NPS) is to protect the natural and cultural resources while still providing public access to the Parks. Balancing the needs of 9.5 million visitors with the ecological needs of the Smokies is an enormous challenge. ${ }^{1}$

One of the largest problems is transporting the ever-increasing number of visitors around the half-million acres, over $95 \%$ of which is forested. A map showing the Park's boundaries and major highways in the surrounding areas is shown in Appendix A, Figure A.1. Transportation within the Park presents many issues, including congestion, damage to the environment, impacts on safety, and a degraded visitor experience.

\subsection{Purpose of this Document}

Currently, private vehicles provide the only mode of transportation within the Park boundaries, with one exception. ${ }^{2}$ The purpose of this report is to document the transportation dilemma within the Smokies, to briefly discuss the concerns of various participants, and to provide a plan for the coordination of stakeholders and interested parties in the development and implementation of potential alternative transportation options. The end result will be a set of recommendations to alleviate the negative impacts of transportation issues within the Park.

\section{$1.2 \quad$ Objectives}

There are five objectives to this study:

- Provide an overview of the current status of transportation issues in the Smokies,

- Collect and document current transit options in and around the GSMNP, especially those relating to the use of Intelligent Transportation System (ITS) technologies,

- Document the interests and activities of agencies, organizations, communities, and other groups involved with the Smokies,

- Identify both technical and institutional barriers to potential implementation of possible solutions to the transportation problems,

- Determine a set of feasible solutions for the areas that have the most serious immediate problems; also provide long-term recommendations for the entire Park, including strategies for coordinating interested organizations, agencies, and other stakeholders.

\footnotetext{
${ }^{1}$ National Park Service, “Great Smoky Mountains National Park,” http://www.nps.gov/grsm/ and associated pages.

${ }^{2}$ The Gatlinburg Trolley, operated by the City of Gatlinburg, Tennessee, has one route that runs into the Park for a short distance. This trolley system is described in greater detail in a later section of this report.
} 


\section{THE SMOKIES - AN OVERVIEW}

Many books and film documentaries have extolled the beauty of the Smokies. The brief overview contained in this chapter barely touches the history of this very special place.

\subsection{A Brief History of the Park}

In 1926, after much debate, Congress authorized a Great Smoky Mountains National Park. Funding for the Park was provided through donations ranging from pennies from school children to a $\$ 5$ million gift from the Rockefeller family. In June 1934, Congress established the Park; in September 1940, President Franklin Delano Roosevelt officially dedicated it. The GSMNP was designated as an International Biosphere Reserve in 1976 and as a World Heritage Site in 1983.

The GSMNP is renowned for its natural resources. The Park is home to over 4,000 species of plants; several native plants and animals live nowhere else in the world! The Park is also known for its cultural history, from the Cherokee Indians to Scotch-Irish settlers. Structures built by early Appalachian settlers include log cabins, barns, churches, grist mills, and other outbuildings. The Park has four distinct seasons, and provides a wide range of recreational options, including hiking, fishing, horseback riding, wildflower viewing, camping, and picnicking, to name a few.

\subsection{Visitation and Budget}

The Smokies are extremely popular and growing more popular each year. Figure 2.1 shows the growth in the number of vehicles entering the Park between 1987 and 1999. In the decade between 1989 and 1999, Park visitation increased by over 34\%.

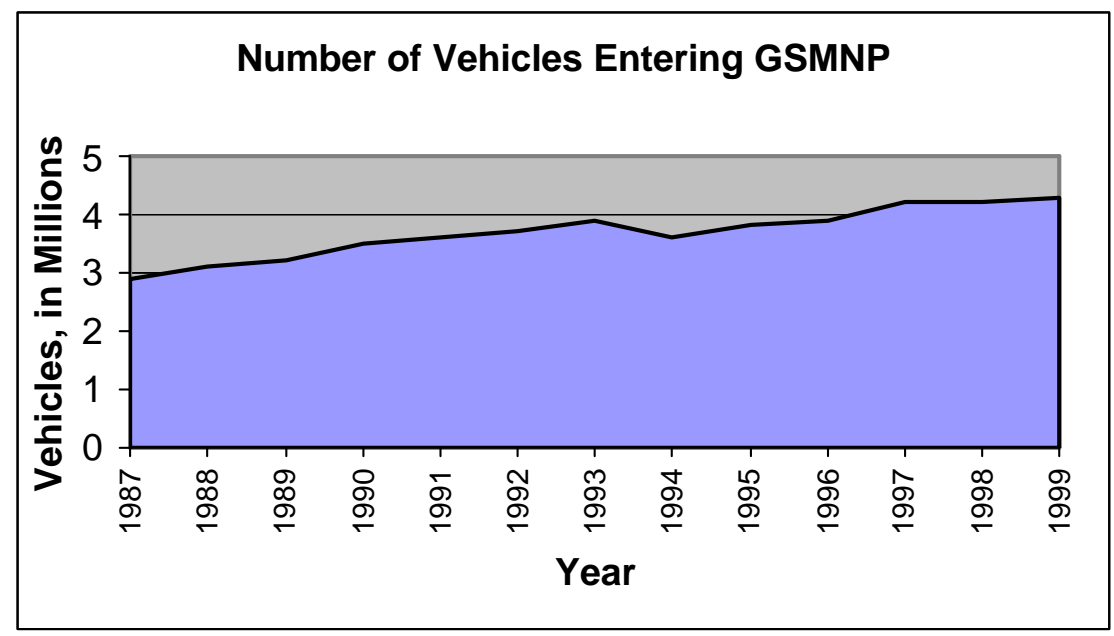

Figure 2.1. Number of Vehicles Entering GSMNP. Source: Mansfield, Duncan, "Visitor Traffic Accelerates in Smokies," The Daily Times, February 7, 2000, pp. 1 and 4a. 
Figure 2.2 compares the annual number of visits to six selected National Parks, three in the eastern United States (Acadia, Shenandoah, and the Smokies) and three in the West (Grand Canyon, Yellowstone, and Yosemite) in five-year intervals since 1980. The Grand Canyon, Yellowstone, and Yosemite Parks were chosen because they are so widely known; however, all of these Parks are located in the western part of the United States. The Acadia and Shenandoah Parks were chosen because they are in the eastern part of the United States, as is the GSMNP. As can be seen in this chart, the total annual visits to the GSMNP are significantly greater than the other Parks and increasing at a higher rate.

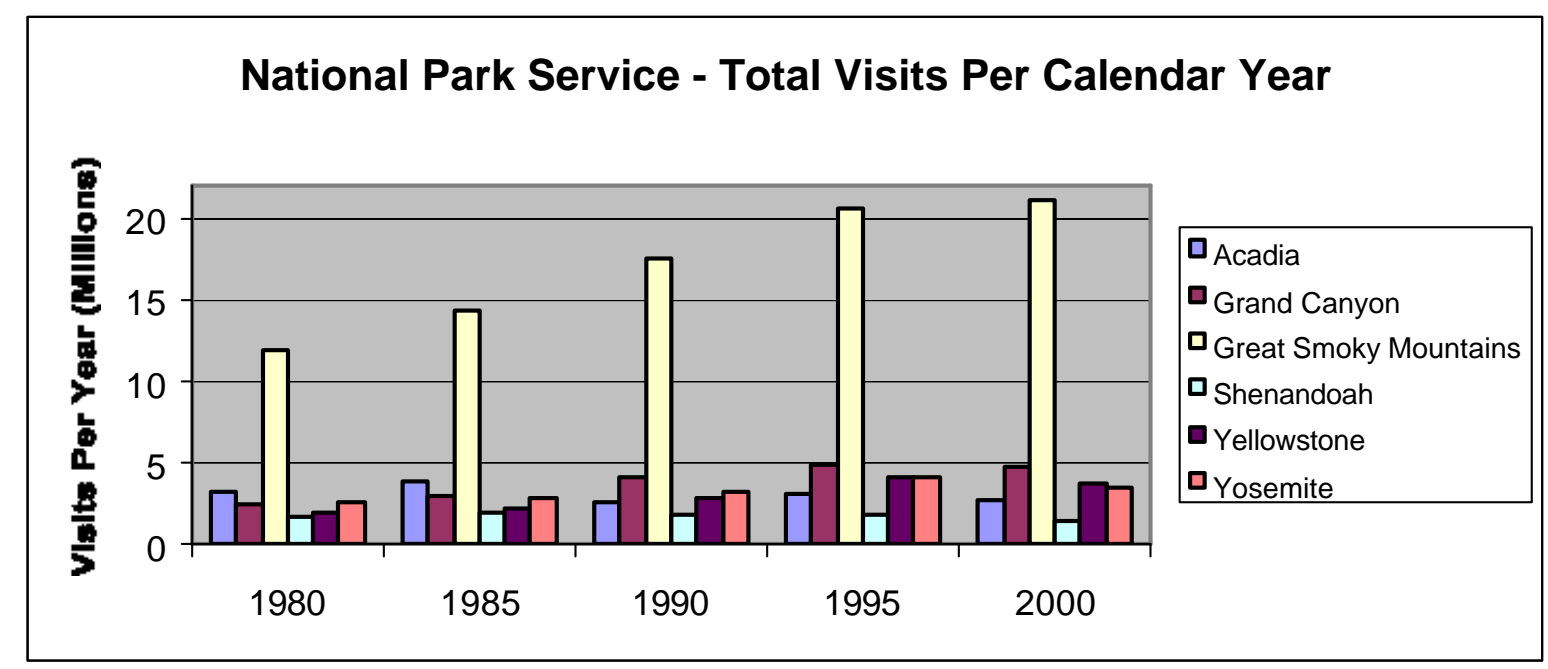

Figure 2.2. Number of Annual Visits to Selected National Parks. Source: National Park Service, Public Use Statistics Office, http://www2.nature.nps.gov/stats/, "Visitation"; "1979-2001 Visitation Database"; "Park Type."

Figure 2.3 shows the relationship of visits to the Parks listed above to the remaining 49 National Parks (Parks only, not including sites such as national battlefields, national lakeshores, etc.) during calendar year 2000. As seen in this chart, visits to the GSMNP represent $23 \%$ of the total visits to National Parks. 


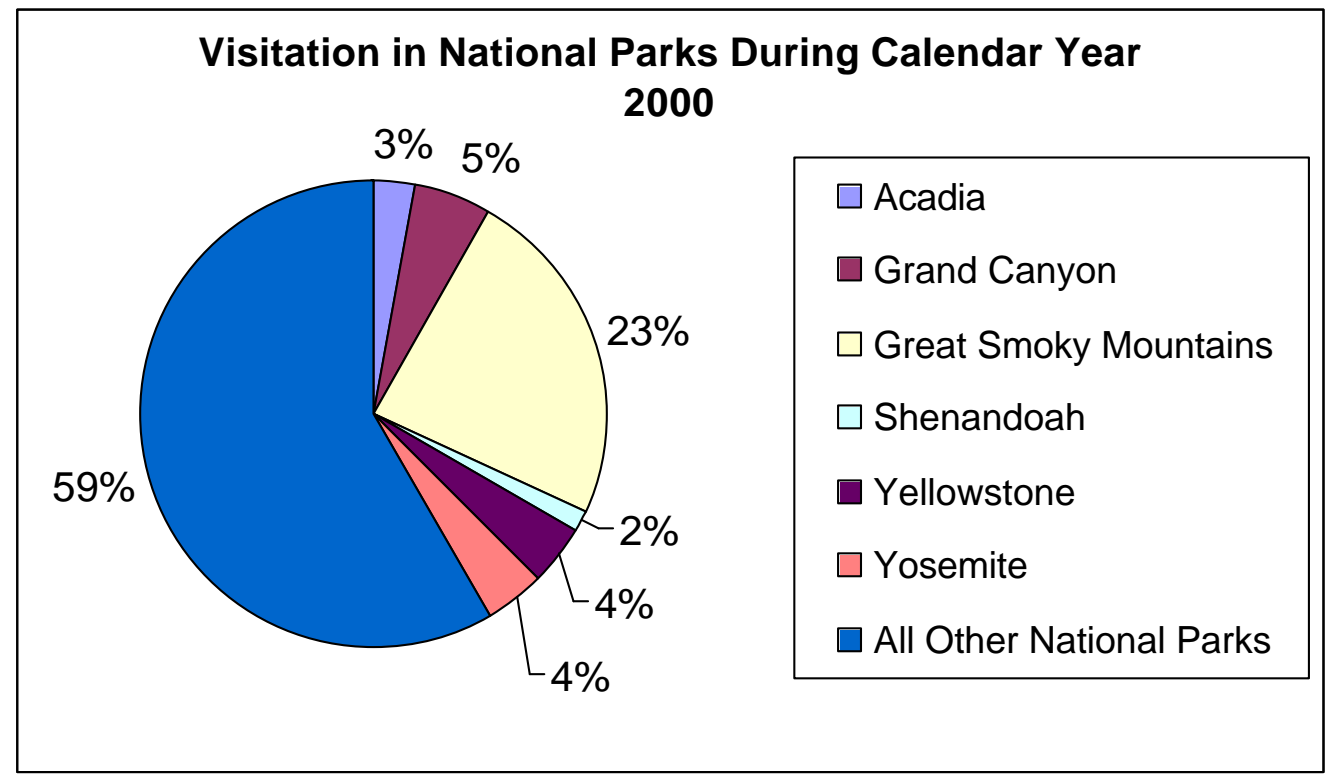

Figure 2.3. Total Visits to National Parks During Calendar Year 2000. Source: National Park Service, Public Use Statistics Office, http://www2.nature.nps.gov/stats/, "Visitation"; "1979-2001 Visitation Database"; "Park Type."

In comparison to the visitation statistics, the Federal funding for the Smokies from the NPS for Fiscal Year (FY) 2000 was only 5\% of the total FY2000 budget. Figure 2.4 shows a comparison of Federal funding for the same Parks shown in Figure 2.3. Figure 2.4 represents budgeted funds for the 55 National Parks only, not all facilities operated by the NPS. 


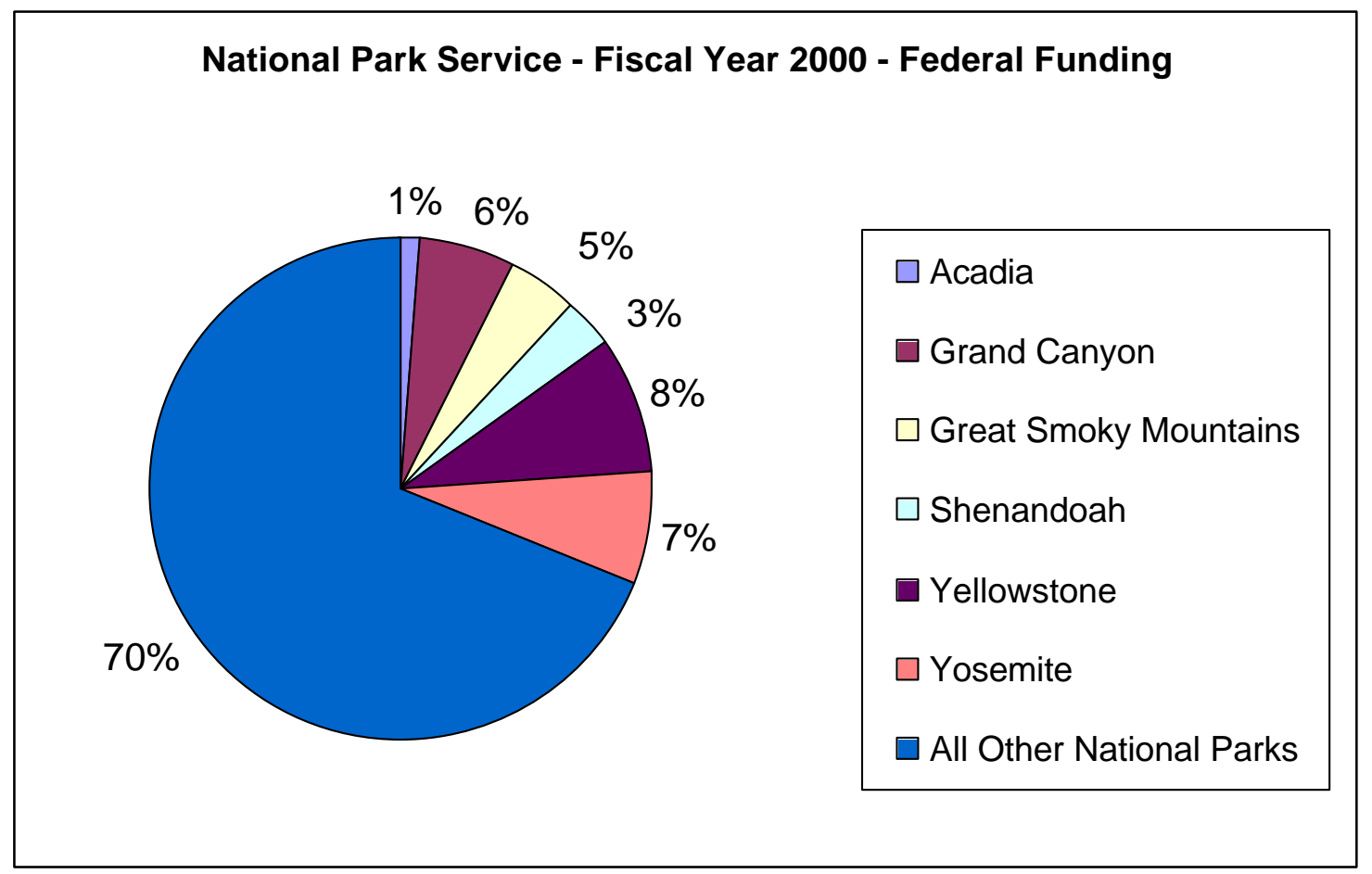

Figure 2.4. Federal Funding for National Parks During Fiscal Year 2000. Source: National Park Service, Budget Justifications and Annual Performance Plan (Greenbook), http://www.nps.gov/budget, "FY 2001"; Park and Program Summary - Park Units by Designation, FY 2000 Enacted.

\subsection{Geographical Perspective and Gateway Communities}

The GSMNP encompasses parts of Tennessee and North Carolina. The Park is contained within Blount, Sevier, and Cocke counties in Tennessee and Graham, Swain, and Haywood counties in North Carolina. A map showing the Park's boundaries, county lines, and locations of gateway communities is shown in Appendix A, Figure A.2.

The primary gateway communities in Tennessee are Townsend, Gatlinburg, Pigeon Forge, Sevierville, and Pittman Center. The primary gateway communities in North Carolina are Fontana Village, Bryson City, Cherokee, and Maggie Valley. A description of these towns is provided in Table 2.1 . 


\begin{tabular}{|c|c|c|c|c|}
\hline \multicolumn{5}{|c|}{ Table 2.1. Gateway Communities to the Smokies } \\
\hline \multirow[t]{2}{*}{ Town } & \multicolumn{2}{|c|}{$\begin{array}{l}\text { Approximate } \\
\text { Population }\end{array}$} & \multirow{2}{*}{$\begin{array}{l}\text { Highway to } \\
\text { Smokies }\end{array}$} & \multirow[t]{2}{*}{ Principal Attractions } \\
\hline & $\begin{array}{c}1990 \\
\text { Census }\end{array}$ & $\begin{array}{c}2000 \\
\text { Census }\end{array}$ & & \\
\hline \multicolumn{5}{|c|}{ Tennessee } \\
\hline Townsend & 386 & 244 & U.S. 321; TN 73 & $\begin{array}{l}\text { Tourist attractions, recreational pursuits, } \\
\text { lodging }\end{array}$ \\
\hline Gatlinburg & 3355 & 3382 & U.S. 441 & $\begin{array}{l}\text { Shopping, wedding chapels, crafts, } \\
\text { entertainment }\end{array}$ \\
\hline Pigeon Forge & 3168 & 5083 & U.S. 441 & $\begin{array}{l}\text { Shopping, wedding chapels, crafts, } \\
\text { entertainment (e.g., Dollywood) }\end{array}$ \\
\hline Sevierville & -- & 11757 & U.S. 441 & $\begin{array}{l}\text { Shopping, wedding chapels, crafts, } \\
\text { baseball (Tennessee Smokies) }\end{array}$ \\
\hline Pittman Center & 404 & 477 & U.S. 321 & Tourist cabins \\
\hline \multicolumn{5}{|c|}{ North Carolina } \\
\hline $\begin{array}{l}\text { Fontana Village } \\
\text { (Graham County) }\end{array}$ & -- & $\begin{array}{l}7993 \\
\text { (entire } \\
\text { county) }\end{array}$ & U.S. 129; NC 28 & $\begin{array}{l}\text { Lodging, recreational pursuits, tourist } \\
\text { attractions }\end{array}$ \\
\hline Bryson City & 1145 & 1411 & U.S. 74 & Lodging \\
\hline $\begin{array}{l}\text { Cherokee } \\
\text { (Eastern Cherokee } \\
\text { Reservation) }\end{array}$ & -- & 8092 & U.S. 441 & $\begin{array}{l}\text { Entertainment (e.g., Harrah's Casino } \\
\text { and an outdoor drama); cultural heritage } \\
\text { (e.g., Indian village) }\end{array}$ \\
\hline Maggie Valley & 207 & 607 & U.S. 19 & Entertainment, recreational pursuits \\
\hline
\end{tabular}

\subsection{Highway Usage Overview}

The Park includes almost 200 miles of paved roads, all of which are either one- or two-lane scenic drives. Primary points of interest within the Park include Cades Cove, Great Smoky Mountain Institute at Tremont, Sugarlands Visitor Center, Clingmans Dome, Newfound Gap, and the Oconaluftee Visitor Center. Directly adjoining the Park is the Cherokee Indian Reservation. All of these sites, which contain interpretive features or displays, have parking lots and are accessible via automobile. ${ }^{3}$ Only one "major" (two-lane, paved) road, U.S. 441, crosses the Smokies. No commercial vehicle traffic is allowed on this road. This highway is currently undergoing major reconstruction on two tunnels and the traffic flow is severely constrained. A map showing primary points of interest within the Park is shown in Appendix A, Figure A.3.

Along most roads within the GSMNP, there are pull-off areas for parking a limited number of vehicles. These areas usually contain picnic tables or are entrances for hikes to especially significant viewing points. Bicycle riding is limited to certain areas during specific days of the week (e.g., the Cades Cove loop road during certain hours).

\footnotetext{
${ }^{3}$ The Park also includes over 1,100 campsites, from primitive to slightly more developed to a "lodge" at Mount LeConte. In addition, 70 miles of the Appalachian Trail (AT) run through the Park. Bear-proof sleeping shelters are positioned along the AT.
} 
The GSMNP appeals to very different tastes and the highway usage characteristics are different based on these tastes as well as on the highway characteristics. This report considers highway usage in three sections of the Park.

\subsubsection{Cades Cove and Western Accesses}

A growing traffic flow is from Townsend, Tennessee (advertised as "the peaceful side of the Smokies"). In 1999, 713,000 vehicles (23\% increase since 1989) entered the Park through Townsend via TN 73. (Over 3.6 million vehicles entered the Park through all other entrances.) Traffic flows are generally reversed for exiting the Park, especially for local traffic. ${ }^{4}$ One major visitation site from this entrance is Cades Cove. Some traffic flows entering the Park from Townsend proceed through the Park to other destinations. For example, TN 73 proceeds through the mountains to the Sugarlands Visitor Center and U.S. Highway 441, which is described in the next section.

Cades Cove is accessible from Townsend via TN 73, a two-lane, paved, winding mountain road. The Cove, which was settled in the 1820s, provides general sightseeing, wildlife viewing, and access to historic mountain cabins, churches, and other buildings. Cades Cove was placed on the National Register of Historic Places in 1977. An 11-mile, one-lane, single-direction paved road loops around the Cove. Surveys show that each vehicle traveling the loop road contains approximately 2.7 persons. Using this figure, the number of visitors to the Cove increased from 1.1 million in 1990 to about 1.8 million in 1998, an increase of almost $64 \%$.

Most of the Cades Cove traffic occurs during four months - June, July, August, and October. October accounts for $18 \%$ of the total yearly visitation because of the outstanding autumn leaf colors. During these peak months, traffic can deteriorate to almost a standstill; the 11-mile route can take as much as four hours to traverse. ${ }^{5}$

A prediction has been made concerning future visitation levels. Based on an analysis conducted for the Knoxville Area Regional Transportation Alternatives Committee (RTAC), a consultant derived a potential growth in visitors to Cades Cove. Based on the predictive model, the Cove simply would be unable to accommodate the demand. (It can hardly accommodate the current level of visitation during October.) According to this study, "The use of an alternative transportation system in the future may be a critical element in allowing visitors who otherwise may not be able to be accommodated to enjoy the Cove."6

\subsubsection{Central Accesses Across the Mountain Between Tennessee and North Carolina}

The only major route through the Park is U.S. 441, which links Cherokee, North Carolina, directly across the mountains via Newfound Gap, with the Sugarlands Visitor Center in

\footnotetext{
${ }_{5}^{4}$ Mansfield, Duncan, "Visitor Traffic Accelerates in Smokies," The Daily Times, February 7, 2000, pp. 1A, 4A.

${ }^{5}$ Cades Cove Technology Assessment Report, August 2001, p. 1-7, http://www.knoxtrans.org/rtap/cadescovereport.htm .

${ }^{6}$ Cades Cove Technology Assessment Report, August 2001, p. 3-4, http://www.knoxtrans.org/rtap/cadescovereport.htm.
} 
Tennessee. From Sugarlands, Highway 441 goes to Gatlinburg, Tennessee. In 1999, 1.6 million vehicles entered the Park via the Gatlinburg entrance (up 11\% since 1989). Over 1.1 million entered via the Cherokee entrance (up 33\% since 1989). Part of this increase may have been brought about by the opening of the Harrah's Cherokee Casino, in Cherokee, North Carolina, in 1997.

The principal traffic flows via Gatlinburg are from I-40 (via TN 66) ${ }^{7}$ and Knoxville, Tennessee (via U.S. 441/Chapman Highway), to and through Sevierville, to and through Pigeon Forge, to and through Gatlinburg, to various locations in the Park and/or to Cherokee. During a peak hour in 1994, the traffic flow on the Sevierville - Pigeon Forge - Gatlinburg corridor exceeded 4,000 vehicles per hour, ${ }^{8}$ and traffic has increased every year.

Some of the sites that are frequently visited in the central section of the Park include the following:

- Sugarlands Visitor Center (Park Headquarters) and Elkmont Campground;

- Newfound Gap - almost literally the center of the Park, it is located along the TennesseeNorth Carolina border;

- Alum Cave Bluffs - common hiking trail; has historical significance because of the alum mine;

- Chimney Tops - hiking trail to twin summits of sheer cliffs; mists from "chimneys" provides an excellent example of how the Smokies got their name;

- Clingman's Dome - the highest spot in the Smokies $(6,643 \mathrm{ft})$;

- Mount LeConte - site of LeConte Lodge;

- Mingus Mill - near Oconaluftee Visitor Center, site of one of two operational water mills in the Park

- Mountain Farm Museum - near Oconaluftee Visitor Center.

\subsubsection{Eastern Accesses}

Interstate-40 is within 4-10 miles of the GSMNP along most of the Park's eastern boundary. Accesses to the Park include Foothills Parkway to Cosby, Tennessee; the Hartford, Tennessee, exit leading to the Appalachian Trail; and the Waterville and Cove Creek exits on the North Carolina side. Obviously, traffic from Asheville, North Carolina, might enter the Park from these Eastern access points or, perhaps more likely, via the Cherokee access.

The Cataloochee Valley is smaller than Cades Cove but contains turn-of-the-century farmhouses, barns, a schoolhouse, and a church. An unpaved road at I-40 and U.S. 276 leads to this site.

\footnotetext{
${ }^{7}$ It should be noted that The Tennessee Smokies baseball team has located its new 6,000-seat stadium with associated parking facilities at the intersection of I-40 and TN highway 66, just off Exit 407.

${ }^{8}$ S. M. Chin, "Foothills Parkway Traffic Study,” December 1996.
} 


\subsection{Issues and Problems}

Transportation issues are a major problem in the Smokies. The primary transportation-related problems in the Park are congestion, environmental degradation and air pollution, impacts on safety, and a diminished visitor experience.

When considering potential solutions to the transportation issues and problems in the Smokies, certain physical characteristics of the geography should be noted. The mountainous terrain along the border between Tennessee and North Carolina shows a good example of the changes in elevation (Figure 2.5).

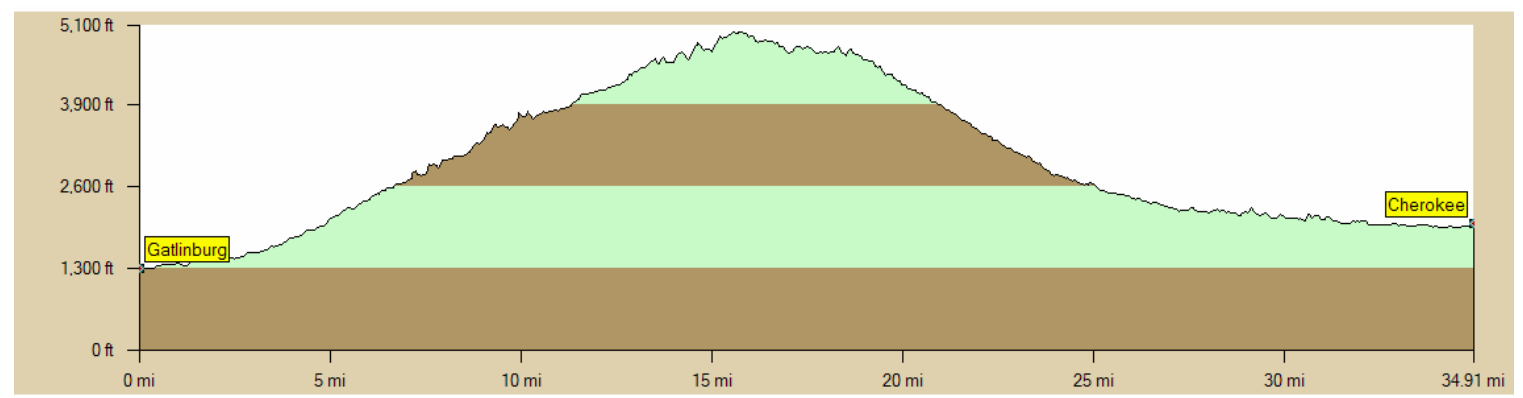

Figure 2.5. Changes in Elevation Between Gatlinburg, Tennessee, and Cherokee, North Carolina, through the GSMNP. Elevation profile prepared using Topo USA ver. 4.0 by DeLorme.

\subsubsection{Congestion}

Traffic congestion through each of the gateway cities and the Park has a significant impact on the economies of the communities and on the environmental conditions within the Park. Major recurring highway congestion limits access to businesses and tourist attractions. Travel through the cities of Sevierville, Pigeon Forge, and Gatlinburg, in Sevier County, Tennessee, can come to a standstill. This same situation can occur in the Park and is exacerbated by the inability to expand the roadways. ${ }^{9}$ While the inability to widen the roadway through the Park is due to environmental consequences and the need to "lie lightly on the land," in the city of Gatlinburg, the primary road cannot be widened because the businesses already abut the road.

\subsubsection{Environmental Degradation and Air Pollution}

The GSMNP is designated as a Class I area. Therefore, it is afforded special consideration when permits are requested for nearby new or modified emissions sources.

In 1990 and 1992, the Department of the Interior issued notices that the Smokies were experiencing adverse environmental impacts including reduced visibility, declines in the spruce

\footnotetext{
${ }^{9}$ Electric Transit Vehicle Institute, Traffic Congestion and Pollution Reduction Assessment of the Great Smoky Mountains National Park and the Gateway Cities of Sevierville, Pigeon Forge and Gatlinburg, ND.
} 
fir forest ecosystem, foliar injury to shrubs and trees, and increased acidity of streams. Federal actions have been taken to

- Reduce the air quality standards for ozone and fine particulates,

- Call for revised State Implementation Plans to reduce emissions for utilities and industries,

- Implement regional haze rules, and

- Enact tailpipe emission and automotive standards and cleaner fuel requirements. ${ }^{10}$

However, existing Federal requirements are not sufficiently protective of the fragile environment. Ozone levels frequently exceed healthy limits.

Airborne pollutants, including those produced by automobile exhaust systems, are degrading the environmental resources of the Park. In 1998, there were 44 days when air quality warnings were issued to the public. In 1999, the Park had 51 unhealthy air days.

The GSMNP has four air quality monitoring stations. According to the NPS, three of these stations are in the "top" five locations for ozone levels, and the fourth ranks as 15th (Figure 2.6). The 1997-1999 average air quality at the stations at Look Rock, Cove Mountain, and Clingmans Dome all violate the 8-hour ozone National Ambient Air Quality Standard of 85 ppb.

A recent study identified the Smokies as the most air-polluted National Park, based on an 11year study of ground-level ozone, acid deposition, and haze. The Smokies air-quality problems "rival" those of Los Angeles and exceed the pollution of other major cities such as Atlanta or New York. ${ }^{11}$

\footnotetext{
${ }^{10}$ Southern Appalachian Mountains Initiative, SAMI: Southern Appalachian Mountains Initiative, Final Report, August 2002, pp. 1.1-1.2.

${ }^{11}$ Simmons, Morgan, "Smokies Smoggier than New York," Knoxville News Sentinel, September 24, 2002, pp. A1, A5.
} 


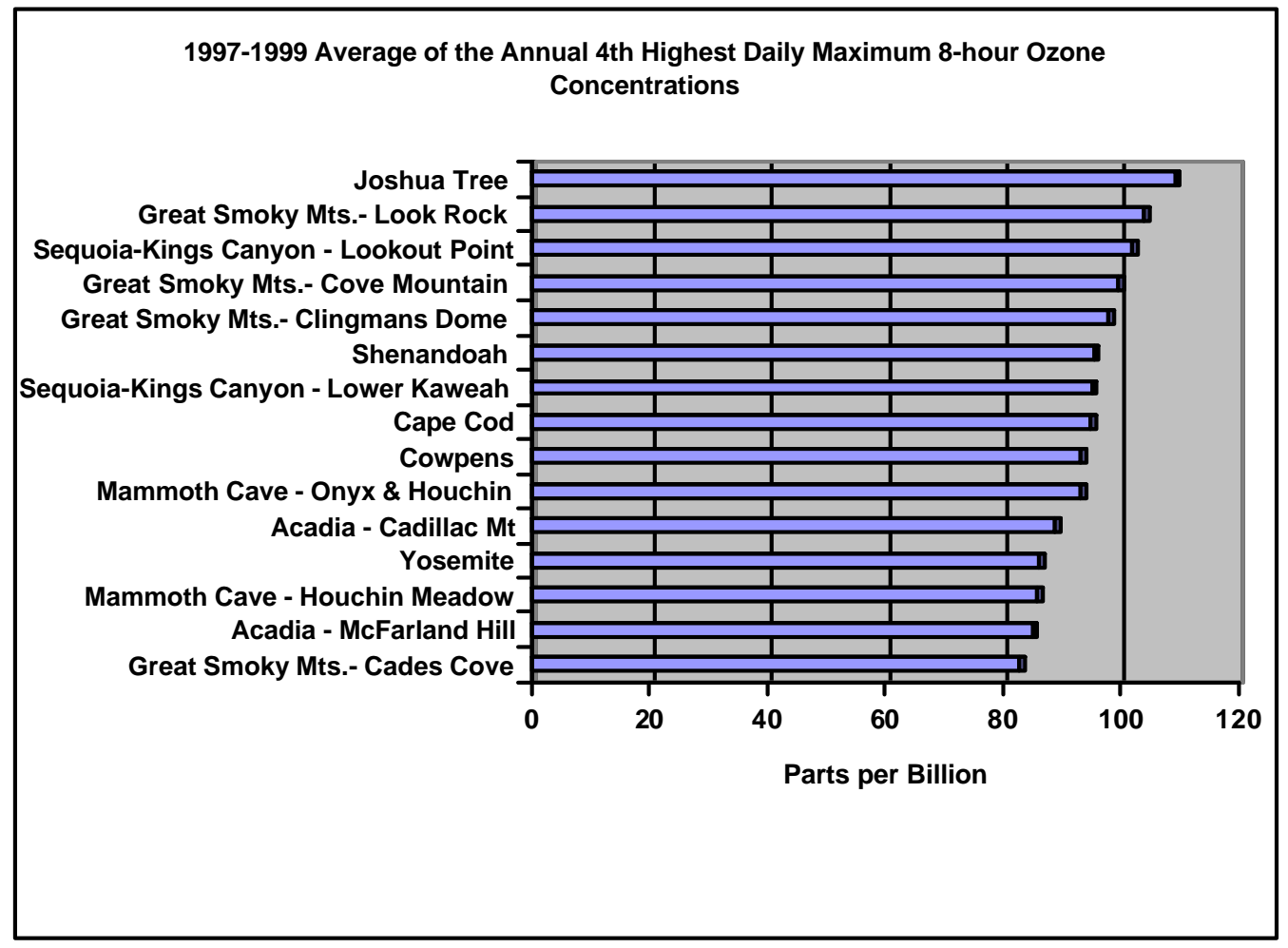

Figure 2.6. Monitoring Locations for Parks with Highest Concentrations of Average $4^{\text {th }}$-Highest Daily Maximum 8-hr Ozone Concentrations, 1997-1999. Note that 85 parts per billion or greater violates the 8-hr ozone National Ambient Air Quality Standard. Source: National Park Service, "List of High Ozone in Park Units - 2001 Season," http://www2.nature.nps.gov/ard/gas/exceed.htm\#priorexceeds .

\subsubsection{Safety}

Safety is an issue in the Smokies for several reasons:

- Two-lane roads with sharp curves, limited shoulders, and other road conditions (e.g., wildlife) that could be hazardous;

- Difficulties in clearing accidents and long distances to transport the injured to hospitals;

- Road rage because of excessive congestion;

- Issues with pedestrians at parking areas because of limited parking facilities. 


\subsubsection{Visitor Experience}

Surveys of Park visitors indicate that the primary reason to visit the Smokies is to view the scenery. However, over the past 50 years, because of increasing smog and acidic particles, visibility has been reduced by over $60 \%,{ }^{12}$ from over 100 miles to just 23 miles.

In a 1998 visitor use survey, ${ }^{13} 69 \%$ of the respondents (84 of 122) said that the least enjoyable part of their visit was the traffic. The survey respondents were given the opportunity to add individual comments. Many of these comments were related to congestion issues and seemed to favor a transit system.

\subsection{Brief Description of Benefit and Synergy Through Cooperation}

With careful planning, community involvement, and strong State and Federal support, the Smokies will become an area where local residents and tourists alike can move freely and conveniently among the various attractions offered by the gateway communities and by the Park. It is technically possible and environmentally desirable to establish parallel infrastructures and a support environment for automobiles, for pedestrians, and for transit.

The topology of the congested area suggests that some form(s) of mass transit could offer enough benefits to persuade some travelers to leave their personal automobiles while they visit the area. The advantage of a mass transit system over options that would lessen congestion but, at the same time, increase the number of passenger vehicles is that it would address environmental problems at the same time that it is assisting economic growth. Fewer privately operated vehicles within the Park implies less air pollution; mass transit implies that even more tourists can enjoy the Smokies (already the nation's most visited National Park) and surrounding communities and tourist attractions. A mass transit system for the GSMNP has three primary strategic objectives:

- To provide a sustainable economic boost to the area,

- To address environmental (i.e., air pollution) issues,

- To provide relief from traffic congestion.

\footnotetext{
${ }^{12}$ Electric Transit Vehicle Institute, Traffic Congestion and Pollution Reduction Assessment of the Great Smoky Mountains National Park and the Gateway Cities of Sevierville, Pigeon Forge and Gatlinburg, ND.

${ }^{13}$ Wilbur Smith Associates, "Regional Transportation Alternatives Plan for East Tennessee," prepared for Knoxville Urban Area Metropolitan Planning Organization, p. 1-9, May 2000 (“Access Issues at Cades Cove," Summary of findings from charette conducted in May 1998).
} 


\section{POTENTIAL TRANSIT INTELLIGENT TRANSPORTATION SYSTEM TECHNOLOGIES WITHIN AND/OR NEAR THE PARK}

\subsection{ITS Technologies for Transit}

ITS technologies are a collection of technologies that increase the efficiency and the safety of public transportation systems and offer users greater access to information on system operations. Implementation of ITS technologies is transforming the way that public transportation systems are operated and changing the nature of the transportation services that can be offered by public transportation systems. The goal is to provide public transportation decision-makers more information to make effective decisions on systems and operations as well as to increase travelers' convenience and the ridership.

Based on a recent study by the Volpe National Transportation Systems Center, ${ }^{14}$ ITS technologies can be organized into five broad categories that describe the technologies' relevance to transit applications. Each category is comprised of a variety of technology choices that are available to help transit agencies and organizations to meet travelers' service needs while increasing safety and efficiency. The five ITS technology categories are:

! $\quad$ Fleet Management Systems

- Automatic Vehicle Location Systems

- Transit Operations Software

- Communications Systems

- Geographic Information Systems

- $\quad$ Automatic Passenger Counters

- Traffic Signal Priority Systems

! Traveler Information Systems

- $\quad$ Pre-Trip Transit and Multimodal Traveler Information Systems

- In-Terminal/Wayside Transit Information Systems

- In-Vehicle Transit Information Systems

! Electronic Payment Systems

- Smart Cards

- Fare Distribution Systems

- Clearinghouse

! Transportation Demand Management

- Dynamic Ridesharing

- Automated Service Coordination

- Transportation Management Centers

\footnotetext{
${ }^{14}$ Volpe National Transportation Systems Center, Advanced Public Transportation Systems: The State of the Art Update 2000, December 2000.
} 
! The Transit Intelligent Vehicle Initiative

- Lane Change and Merge Collision Avoidance

- Forward Collision Avoidance

- Rear Impact Collision Mitigation

- Tight Maneuvering/Precision Docking

\subsection{County-Based Demand-Response-Only Transit Services}

Transit agencies that provide demand-response-only services in the study area include East Tennessee Human Resource Agency in Tennessee, Swain Transit, Mountain Projects Inc., and Eastern Band of Cherokee Indians in North Carolina. Currently, no ITS transit technology is implemented by these agencies.

Even the largest of these transit systems around the GSMNP is small in contrast to the overall level of operations in many urban public transit systems. This small size creates large challenges in terms of funding technological improvements and, then, realizing their intended productivity and economic benefits at the level of the individual rural transit system.

\subsection{Fixed-Route Trolley Systems}

Both Pigeon Forge Fun Time Trolleys and Gatlinburg Mass Transit System are serving the GSMNP tourist areas. These systems can be characterized by their large seasonal variations in demand and by their congestion during the peak tourist season. Potential ITS applications for these regions include traveler information systems, dynamic routing, and automated public address systems. Currently, no ITS transit technology has been implemented for these two transit agencies.

The Electric Transit Vehicle Institute (ETVI), a nonprofit organization, promotes the design, production, and use of battery-powered electric and hybrid-electric vehicles. Through Transit Support, Technology Transfer and Education Outreach, ETVI supports individuals and organizations interested in learning more about electric and hybrid-electric vehicles, particularly electric buses. Under the sponsorship of the Tennessee Department of Transportation (TDOT) and the Federal Highway Administration, ETVI demonstrated the use of a hybrid-electric bus on several of the regular trolley routes serviced in Gatlinburg ${ }^{15}$ and Pigeon Forge ${ }^{16}$ in 1998. These demonstrations gave city representatives, transit professionals, and residents a unique opportunity to see the benefits of electric buses first-hand.

\subsection{Commercial Bus Tours}

In addition to public founded transit services, several commercial tour bus companies ${ }^{17}$ also provide daily services from different city origins to the Eastern Band of Cherokee Indians

\footnotetext{
${ }^{15}$ Tennessee Department of Transportation, Hybrid-Electric Bus Charges Winter Light Festival, TDOT Electric Bus Demonstration project Newsletter, Issue 3, January 1999.

${ }^{16}$ Tennessee Department of Transportation, A Breath of Fresh Air Visits Pigeon Forge, TDOT Electric Bus Demonstration project Newsletter, Issue 1, October 1998.

${ }^{17}$ Casino Tours - Atlanta, GA, Catawba Valley - Catawba, NC, Slots On The Run - Charlotte, NC and Columbia, SC, Pat Owensby - Greensboro, NC, Fun Tours - Hickory, NC, Sunshine Tours - Yadkinville, NC, Video Game Plus - Greenville, SC, 
Reservation, which is adjacent to the southeastern side of the GSMNP. The nature of these commercial tour bus services is different from mass transit services.

\subsection{Conclusion}

Some technologies (e.g., electronic fare collection and transit operation information dissemination through the Internet) can help local transit systems. Other technologies (e.g., automated vehicle location system and computer-aided dispatching systems) will probably be beneficial, but not be economically justified, to schedule demand-response van reservations and insert new demand. Detailed studies are needed to help the transit agencies around GSMNP to select the best ITS technologies to increase the efficiency and safety of their public transportation systems and offer users a greater access to information on system operations. A report by TransCore ${ }^{18}$ has outlined the step-by-step procedures to evaluate the needs of rural transit agencies and to apply ITS technologies.

and D\&M Tours - Chattanooga, TN.

${ }^{18}$ TransCore, Rural Public Transportation Technologies: User Needs And Applications - Final Report, July 1998. 


\section{MASS TRANSIT SERVICES AROUND THE GREAT SMOKY MOUNTAINS NATIONAL PARK}

Primary gateway communities of the GSMNP are located in both North Carolina and Tennessee. Mass transit services around the GSMNP in both North Carolina and Tennessee will be briefly described in the following sections.

\subsection{Mass Transit Services in Tennessee}

Currently, TDOT's Office of Public Transportation (OPT) in the Public Transportation, Waterways, and Rail Division provides financial assistance for the operation of 23 public transit systems serving all counties in the State. Depending on specific needs of the community, various services are provided. They include rail, fixed-route bus, demand-response minivan or van, and trolley. In Tennessee, there are twelve urban transit providers and eleven rural transit providers. Among these transit service providers, two urban providers (i.e., Gatlinburg Mass Transit System and Pigeon Forge Fun Time Trolleys) and one rural transit provider (i.e., East Tennessee Human Resource Agency) are providing transit services to gateway communities on the Tennessee side of the GSMNP.

\subsubsection{East Tennessee Human Resource Agency (ETHRA)}

Since its establishment in 1974, the activities and responsibilities of ETHRA have grown significantly. The programs, ranging from services for infants and children to services for senior citizens, reach deeply into the roots of all East Tennessee communities. As a part of its many services, ETHRA provides demand-response van services in 16 Eastern Tennessee counties (Figure 4.1). ${ }^{19}$ This transportation service enhances mobility and accessibility of residences in non-urbanized areas to health care, shopping, education, employment, public services, and recreation.

There is no restriction on who can use ETHRA's van service. Current hours of operation are 8:00 a.m. to 4:30 p.m. from Monday through Friday. Interested residents are required to make their reservations at least 48 hours in advance to schedule a trip. A fare of $\$ 1.50$ per trip, or $\$ 3.00$ per round trip, is charged for all in-county trips. An additional $\$ 1.50$ is charged for every county line crossed. All extra stops are $\$ 1.00$.

In theory, residents within ETHRA's service area can use its van service for their recreational trips to the GSMNP. However, it is understood that ETHRA's main focus is to serve residents who have no other means of transportation for medical appointments, essential errands, and employment purposes. Furthermore, the needs for medical trips, essential errands, and employment are so great that often there is little capacity remaining to carry the general public.

\footnotetext{
${ }^{19}$ Anderson, Blount, Campbell, Claiborne, Cocke, Grainger, Hamblen, Jefferson, Knox, Loudon, Monroe, Morgan, Roane, Scott, Sevier, and Union counties.
} 


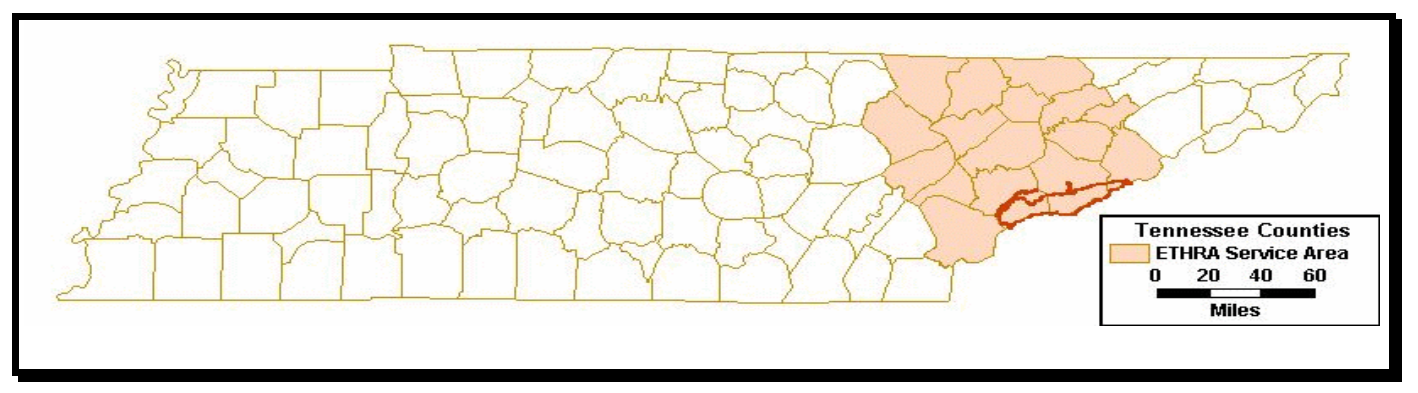

Figure 4.1. ETHRA Service Area. Note that the service area includes the GSMNP.

\subsubsection{Pigeon Forge Fun Time Trolleys}

Pigeon Forge Fun Time Trolleys operates mainly fixed-route trolley bus services for tourists. Hours of operation are from 8:30 a.m. to 12:00 a.m. weekly during tourist season ${ }^{20}$ and special events. The agency operates only two vans for demand-response services.

The Fun Time Trolleys enable tourists to leave their personal vehicles at motels in Pigeon Forge. These trolley buses are air-conditioned and easily accessible to all Pigeon Forge attractions and shops. Trolley buses make frequent stops. They are inexpensive (only 25 cents per ride) and have friendly and informative drivers. Discounted trolley tokens are also available in multiple quantities. A handicapped-accessible trolley is available for pick-up by calling the trolley office 24 hours in advance to make reservations. The trolleys are also available for rental by tourist groups with a 24-hour advance reservation. The fee for this service is $\$ 20.00$ per hour and is available for tours within the city limits. Trips to and from entertainment or major attractions are available at a cost of $\$ 20.00$ each way. No direct service to the GSMNP is provided by the Pigeon Forge Fun Time Trolleys. However, a link between Pigeon Forge and Gatlinburg trolleys is available.

\subsubsection{Gatlinburg Mass Transit System}

Gatlinburg Mass Transit System provides fixed-route trolley bus service mainly for tourists. To a limited extent, it also serves local residents and workers. In addition to trolley buses, the agency also operates demand-response services. The trolley bus service enables tourists to visit all shops and attractions in and around the City of Gatlinburg without driving their personal vehicles.

The Gatlinburg Mass Transit System operates its trolley buses year round, but with modified routes and reduced schedules during the winter seasons. Typically, these trolley buses are operated 16 hours a day except in the winter months. The Gatlinburg Trolley Department has 15 large trolleys with a seating capacity of 28 to 36 and four mini-trolleys with seating capacity of 16 to 20. Furthermore, the Gatlinburg Mass Transit has trolleys that are handicap-equipped. It also has a special van that can go to motels to pick up physically challenged passengers. This special handicap-equipped van is operated as an on-demand service with a 24 -hour advance notice.

\footnotetext{
${ }^{20}$ Operates between 10:00 a.m. to 10:00 p.m. during November and December and does not operate in January, February, and March.
} 
Trolley fare for the Galinburg Mass Transit System is 25 cents per person, with a few exceptions. The fare for the Dollywood Trolley is 75 cents per person, the Arts and Crafts Trolley route is $\$ 1.00$, and the National Park Trolley route is $\$ 2.00$ per round trip. The base cost for the demandresponse van is 50 cents for a local trip and $\$ 1.00$ for a Dollywood trip. An annual pass is available for residents at $\$ 10.00$ per person and $\$ 4.00$ per person for the local labor force.

The National Park Trolley (Figure 4.2) runs between 11:00 a.m. to 9:00 p.m., from June through October. The route begins at the Gatlinburg Mass Transit Center. The trolley runs down River Road and then onto the Parkway into the GSMNP. Stops include the Sugarlands Visitor Center, Laurel Falls Parking Area, and Elkmont Campground before returning to Gatlinburg. A trip lasts about 1.5 hours. Exact change is required for riding this bus. In 2001, 2,953 persons used this service. Gatlingburg Mass Transit considers this service route as successful. However, there is no plan to expand service to other parts of the GSMNP. This trolley bus route is the only mass transit service that serves the GSMNP.

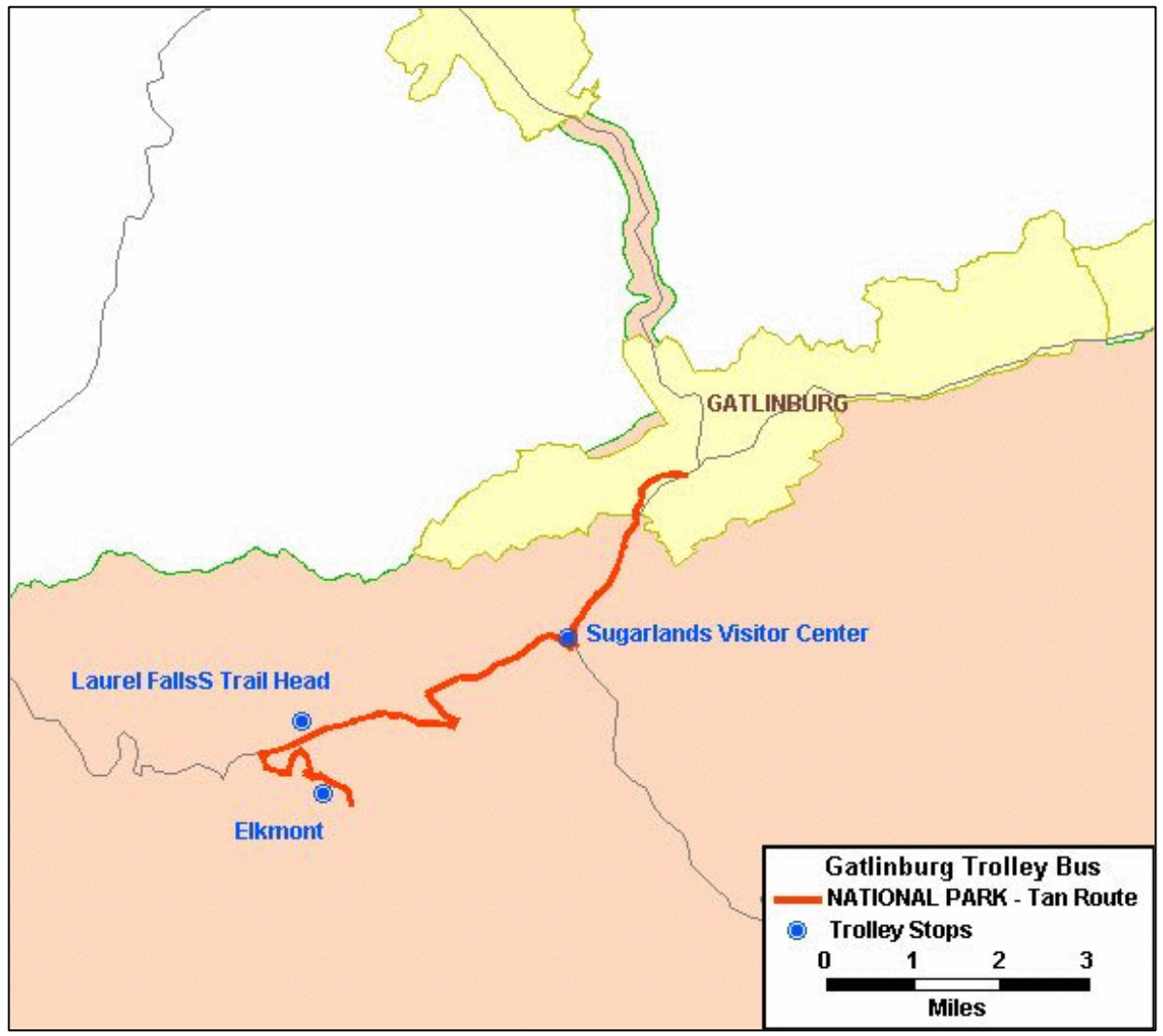

Figure 4.2. National Park Trolley Route Provided by the Gatlinburg Mass Transit System. 


\subsection{Mass Transit Services in North Carolina}

The North Carolina Department of Transportation (NCDOT) Public Transportation Division helps North Carolina public transit systems in moving people. NCDOT does not operate buses, trains, or vans directly, because this responsibility belongs to local transit systems. The Public Transportation Division does, however, help the local systems to operate safer and more effectively. More than 100 urban and rural public transportation systems serve millions of North Carolinians in all counties within the State. By combining the Public Transportation Division resources with local communities and transportation providers, NCDOT has helped make public transit in North Carolina more efficient.

Currently, no fixed-route traditional type of urban mass transit service is provided to the GSMNP gateway communities in North Carolina. There are demand-response van services in two counties (Swain and Haywood), which are adjacent to the GSMNP.

\subsubsection{Swain County}

Swain Transit is providing community transportation service within Swain county. This agency provides subscription and dial-a-ride transportation services for its county residents. The hours of operation for this service are from 5 a.m. to 6 p.m., Monday through Friday. These transportation services are offered to the general public starting at $\$ 1.00$ per trip and the charges increase based on travel zones. Out-of-county medical transportation is also provided on a daily basis.

In addition, the Eastern Band of Cherokee Indians provides transportation services for certain authorized residents within its qualia boundary. This includes tribal areas in Swain County and neighboring Jackson County. The hours of operation for this service are from 6:00 a.m. to 6:00 p.m., Monday through Friday. Currently, there are no general public routes in this area.

\subsubsection{Haywood County}

Haywood PublicTransit, offered through the Mountain Projects Inc., provides subscription and dial-a-ride transportation for residents of Haywood county. Its hours of operation are from 6:00 a.m. to 6:30 p.m., Monday through Friday. General public fare is $\$ 3.00$ for one-way trips within most areas of the county.

As with many rural community transit programs, the main focus of these two transportation agencies in Swain and Haywood counties is to serve residents who have no other means of transportation to access medical services, essential errands, and employment opportunities. Recreational trips to GSMNP are not part of these programs' focuses.

\subsection{Harrah's Cherokee Casino Bus}

The Eastern Band of Cherokee Indians Reservation is nestled at the south edge of the GSMNP. The Cherokee Indians operate a Native American gambling casino, called Harrah's Cherokee Casino, in Cherokee, North Carolina. In order to promote casino business, the Harrah's Cherokee Casino has been working with local tour bus companies to provide scheduled bus services to the 
casino from Atlanta, Georgia; Catawba, Charlotte, Greensboro, Hickory, and Yadkinville in North Carolina; Columbia and Greenville in South Carolina; as well as Chattanooga, Tennessee.

However, none of these bus services make any stops in the GSMNP.

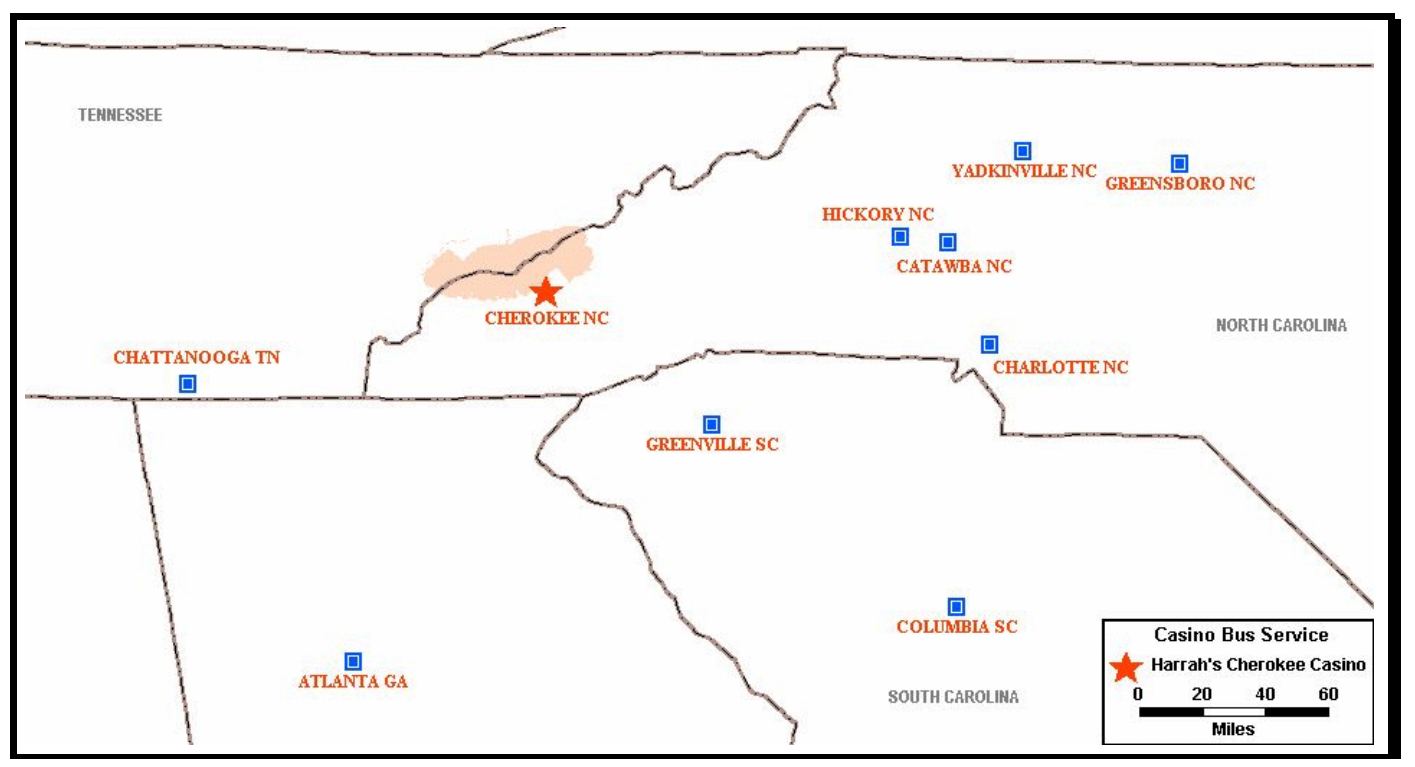

Figure 4.3. Origin Points for the Harrah's Cherokee Casino Bus.

\subsection{Contact Information for Transit Agencies Serving the Gateway Communities Around GSMNP}

The following contact information is for transit agencies that serve the gateway communities around the GSMNP:

\begin{tabular}{|l|l|}
\hline Melinda Britton, Administrator & Charles G. Reagan, Trolley Director \\
East Tennessee Human Resource Agency & City of Pigeon Forge Fun Time Trolleys \\
298 Blair Bend Road & 186 Old Mill Avenue \\
Loudon, TN 37774 & Pigeon Forge, TN 37863 \\
865 408-0843 and 800 232-1565 & 865 453-6444 \\
\hline Buddy Parton, Mass Transit Director & Swain Transit \\
Gatlinburg Mass Transit System & P.O. Box 356 \\
P.O. Box 5 & Bryson City, N.C. 28713-0356 \\
Gatlinburg, TN 37738 & 828 488-3047 \\
865 436-3897 & \\
\hline Eastern Band of Cherokee Indians & Haywood PublicTransit, c/o Mountain Projects Inc. \\
P.O. Box 455 (Tsali Manor) & 2251 Old Balsam Road \\
Cherokee, N.C. 28719-0455 & Waynesville, N.C. 28786-0732 \\
828 497-5296 & 828 452-1447 \\
\hline Richard "Twidge" Welch, Group Sales & \\
Harrah's Cherokee Casino & \\
777 Casino Drive & \\
\hline
\end{tabular}


Cherokee, NC 28719

828 497-8882

Tour Bus Operators for Services to Harrah's Cherokee Casino:

\begin{tabular}{|l|l|}
\hline Casino Tours & Slots On The Run \\
Atlanta, GA & Charlotte, NC and Columbia, SC \\
678 446-7777 & $803714-7105$ \\
\hline Catawba Valley & Pat Owensby \\
Catawba, NC & Greensboro, NC \\
828 256-9461 & $336292-4439$ \\
\hline Fun Tours & Sunshine Tours \\
Hickory, NC & Yadkinville, NC \\
828 325-0333 & 336 679-2656 \\
\hline Video Game Plus & D\&M Tours \\
Greenville, SC & Chattanooga, TN \\
864 235-6796 & 423 867-5808 \\
\hline
\end{tabular}




\section{PARTICIPANTS AND INTERESTED PARTIES}

The purpose of this chapter is to pull together in one section a listing of groups that are interested in the transportation problems in the Smokies and to provide a brief description of their efforts. As much information will be provided as is appropriate and/or feasible within the space constraints of this document.

\subsection{Federal Agencies and Other National Organizations}

Several Federal agencies are interested in issues concerning the National Parks. Two primary participants are the Department of Interior (DOI) and the Department of the Transportation (DOT).

\subsubsection{Department of Interior}

Of the eight major bureaus within the DOI, three have particular interests in the GSMNP: the Fish and Wildlife Service, the Bureau of Indian Affairs, and the NPS. The Fish and Wildlife Service manages National Wildlife Refuges and National Fish Hatcheries and is not directly involved with the National Parks. If, however, transportation options were to be considered that might impact protected species, the Fish and Wildlife Service's Endangered Species Program would become involved. The Bureau of Indian Affairs is involved because of the Cherokee Indian Reservation adjacent to the Park on the North Carolina side and because of the possibility for disturbing Indian antiquities during potential construction of transit options.

The primary bureau within Interior, however, with interest in the Smokies is the NPS. The mission of the NPS is to "preserve unimpaired the natural and cultural resources and values of the National Park System for the enjoyment, education, and inspiration of this and future generations. The Park Service cooperates with partners to extend the benefits of natural and cultural resource conservation and outdoor recreation., ${ }^{, 21}$ Developing transportation solutions for the Smokies that enhance visitor enjoyment and do not harm the environment requires planning, coordination, and creativity. Options may include non-traditional modes, such as transit and recreational trails; ITS technologies are essential. Certainly an integrated approach involving the gateway communities, if not the entire region, is essential.

In November 1997, DOI and DOT entered into a Memorandum of Understanding (MOU) to meet the challenge of preserving the Parks while still allowing visitor access. ${ }^{22}$ One component of the MOU was to provide an opportunity for a field operational test of ITS technologies. However, the Smokies were not considered as a field test site.

\subsubsection{Department of Transportation}

In addition to the MOU between Interior and Transportation (Section 5.1.1) specific agencies within the DOT that are interested in Smokies transportation issues include the Federal Highway Administration (FHWA) and the Federal Transit Administration (FTA). As part of the

\footnotetext{
${ }^{21}$ Department of the Interior, Strategic Plan, FY2000 - FY2005,. http://www.doi.gov/gpra/doi.pdf .

${ }^{22}$ National Park Service, "Alternative Transportation in the National Parks, Memorandum of Understanding between Secretary of Transportation and Secretary of the Interior," http://www.nps.gov/transportation/alt/mou.htm .
} 
Transportation Equity Act for the $21^{\text {st }}$ Century (TEA-21), a study was conducted of national alternative transportation system needs in National Parks and other federal lands. ${ }^{23}$ As noted in this study, the impacts of visitors on the National Parks is due less to the number of visitors than it is to the number of automobiles. Issues that can be addressed through the use of transit include the following:

- Transportation issues such as parking problems and traffic congestion,

- Resource preservation issues,

- Economic and community development issues (e.g., Gatlinburg, Tennessee, is economically dependent on tourism),

- Recreational issues, and

- Tribal issues. ${ }^{24}$

According to this study, the GSMNP has new transit needs as well as a need to improve the existing trolley system that has a limited route into the Smokies from Gatlinburg. ${ }^{25}$

Transportation issues are being addressed at several National Parks. For example, in 1998, FHWA stationed a planner at Yosemite National Park. Acadia National Park was selected as a demonstration site for an ITS Field Operation Test. The alternative-fueled buses at Acadia are considered a tremendous success. Zion Canyon also uses a shuttle bus, and the Grand Canyon National Park has constructed a light rail transit line. ${ }^{26}$

\subsubsection{Department of Energy}

In April 1999, the Green Energy Park program was initiated between the Department of Energy (DOE) and the DOI. The purpose of the Green Energy Park program was to help promote sustainable energy projects and to educate Park visitors about innovative energy technologies. In December 1999, 32 National Parks received financial incentive awards to advance the use of alternative fuels. According to Bill Richardson, former Secretary of Energy, "Using alternatively fueled vehicles and more effective and efficient transit systems can significantly reduce pollution and contribute to a better visitor experience."27 The Smokies was not one of the recipients in $1999 .{ }^{28}$ In 2000, the Green Energy Parks Alternative Fuel Project List named the GSMNP as one of six recipients in the Southeast Region; however, the Park did not receive the grant. ${ }^{29}$ It is believed

\footnotetext{
${ }^{23}$ Federal Highway Administration and Federal Transit Administration, Federal Lands Alternative Transportation Systems Study: Volume 3: Summary of National ATS Needs, August 2001, http://www.fta.dot.gov/library/policy/fedland/v3/index.html .

${ }^{24}$ Federal Highway Administration and Federal Transit Administration, Federal Lands Alternative Transportation Systems Study: Volume 3: Summary of National ATS Needs, Chap. 3, August 2001, http://www.fta.dot.gov/library/policy/fedland/v3/issue.pdf .

${ }^{25}$ Federal Highway Administration and Federal Transit Administration, Federal Lands Alternative Transportation Systems Study: Volume 3: Summary of National ATS Needs, Chap. 4, p. 4-9, August 2001, http://www.fta.dot.gov/library/policy/fedland/v3/asses.pdf .

${ }^{26}$ Turnbull, Katherine F., "Visitor Transportation at U.S. National Parks; Increasing Accessibility but Preserving the Environment," pp. 3-8 in TR News, September-October 2000.

27 Richardson, Bill, "Green Energy," pp. 39-40 in National Parks, January/February 2000.

${ }^{28}$ Department of Energy, "Department of Energy Awards Alternative Fuel Grants to 32 National Parks," http://www.energy.gov/HQPress/releases99/decpr/pr99319.htm.

${ }^{29}$ Palazzolo, Chiara, Personal phone conversation with Tykey Truett, September 25, 2002.
} 
that the reason the funds were not distributed was because the cost-sharing partnership fell through. $^{30}$

In June 2000, DOE signed an agreement with the NPS to encourage energy efficient technologies and alternative transportation systems at Parks throughout the southeast. The agreement, part of the Green Energy Parks Initiative, was a regional approach to meeting energy conservation goals. ${ }^{31}$ In November 2000, DOE and the NPS announced \$1.6 million in funding for 70 new clean energy projects in the Parks. In FY2001, DOE and NPS committed \$2.0 million in funding for 28 new projects. The Smokies has not received any grants.

\subsubsection{Tennessee Valley Authority}

In December 2001, the Tennessee Valley Authority (TVA) and the NPS announced a partnership to use an assortment of electric vehicles in the Smokies for maintenance activities and education programs. The vehicles, which will replace gasoline-fueled vehicles, include electric tractors, bicycles, club cars, and utility vehicles. They will be on loan for two years. ${ }^{32}$

In addition, TVA has started a $\$ 1.5$ billion project to reduce its nitrogen oxide emissions by $75 \%$. This effort will have a large impact on the air quality in the Smokies. ${ }^{33}$

\subsubsection{Environmental Protection Agency}

The Environmental Protection Agency (EPA) is a regulatory agency responsible for researching environmental issues, establishing standards, providing assistance to States and tribes, and issuing sanctions. EPA works with industries and all levels of government. EPA's mission is to "protect human health and to safeguard the natural environment - air, water, and land - upon which life depends."

The goal of the EPA's acid rain program is to reduce emissions of sulfur dioxide and nitrogen oxides. These pollutants degrade water quality, impair visibility, and cause health problems in people, forests, and buildings. The relative deposition of these pollutants in the Smokies is shown in Figure 5.1. Although sulfates (from industrial sources such as coal-fired steam plants) comprise the greatest proportion of the pollutants $(83 \%)$, a major source of nitrates and organic carbon particles $(12 \%)$ is automobile emissions.

During the past few years, air quality in the Smokies has been so bad on some days that people with respiratory problems have been warned to avoid being outside.

\footnotetext{
${ }^{30}$ Farrar-Nagy, Sara, Personal email conversation with Tykey Truett, September 27, 2002.

31 "National Parks to Get Energy Efficient Uplift," June 29, 2000, http://www.energy.gov/HQPress/releases00/junpr/pr00176.htm.

32 "Smokies Partners with TVA: Experiments with Electric Vehicles," December 5, 2001, http://www.nps.gov/grsm/gsmsite/newselectricvehicles.html .

33 "Supporters of Smokies Converge in Townsend," The Daily Times, April 19, 2002, pp. 1, 3A.

Coordination of Transit Concepts in GSMNP
}

page $5-3,11 / 11 / 02$ 


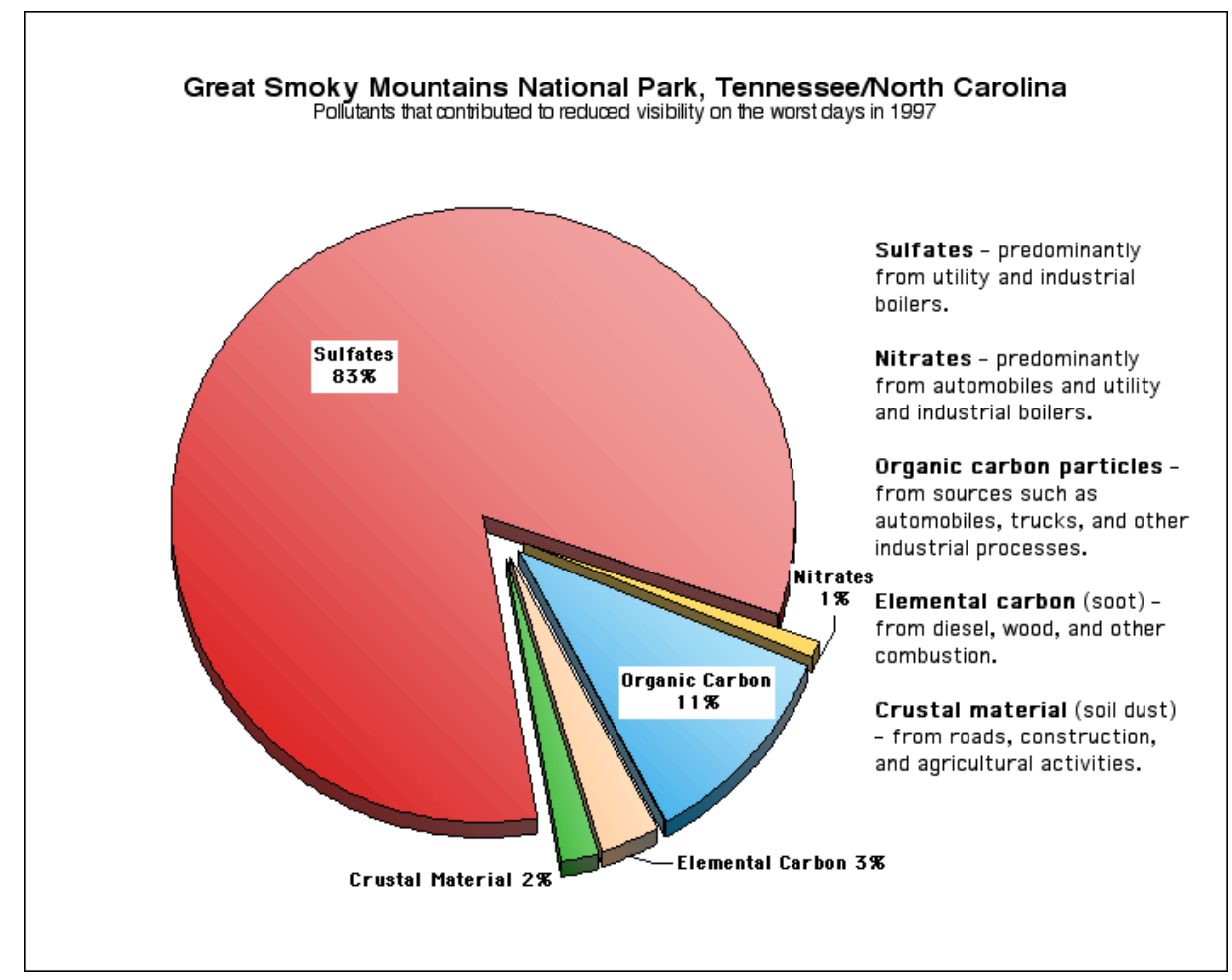

Figure 5.1. Pollutants that Contributed to Reduced Visibility on the Worst Days in 1997. Source: Environmental Protection Agency, "Visibility Impairment," http://www.epa.gov/oar/vis/grsm p.html .

\subsubsection{National Parks Conservation Association}

The National Parks Conservation Association (NPCA), created in 1919, is an advocacy group for the Parks. One of the current projects is to lobby for efficient and cost-effective public transportation systems. NPCA connects grassroots groups in order to combine resources to achieve common goals. NPCA's "Smoky Network" is an affiliation of over 30 organizations with the aim of protecting the GSMNP. ${ }^{34}$ On March 25, 2002, the GSMNP was placed on the NPCA list of Ten Most Endangered Parks for the fourth consecutive year. One of the primary problems is air pollution.

One action advocated by the NPCA is a public mailing to Senator John Edwards (Democrat-NC) to stop construction of a road on the north shore of Fontana Lake in Swain County, North Carolina. The reasons given are that the construction and maintenance of the road would be technically difficult, very expensive, and environmentally damaging. ${ }^{35}$

\footnotetext{
${ }^{34}$ National Parks Conservation Association, “About NPCA,” http://www.npca.org/about_npca/ .

${ }^{35}$ National Parks Conservation Association, "Protect the Smokies - Stop the North Shore Road," http://www.npca.org/take_action/action_alerts/ActionAlert.asp?strAction=link\&lngAlertID=65 .
} 


\subsubsection{National Trust for Historic Preservation}

The National Trust for Historic Preservation was founded in 1949. Its mission is to provide "leadership, education, and advocacy to save America's diverse historic places and revitalize our communities." ${ }^{36}$ In 2001, the National Trust worked with the GSMNP staff and personnel in Sevier County, Tennessee, to organize a task force to focus on the Elkmont area of the Smokies (see Figure A.3). In particular the task force was concerned about the Wonderland Hotel at Elkmont. A Historic Structures Assessment Report found the hotel to be stable but badly deteriorated. Funds are not available for repairs. ${ }^{37}$ Alternate proposals are being developed and reviewed in public hearings.

\subsubsection{National Park Foundation}

The National Park Foundation is a Congressionally chartered nonprofit partner of the National Parks. The Foundation membership includes American Airlines, Discovery, Ford Motor Company, Kodak, and Time. ${ }^{38}$ In mid-April 2002, a \$70,000 grant was made by the National Park Foundation and Ford Motor Company to the Smokies to help coordinate transportation planning options for Cades Cove with the gateway community of Townsend, Tennessee. Using these funds, workshops and public meetings will obtain input from area citizens concerning transportation options and the impact of various strategies on the gateway community's citizens.

\subsubsection{Appalachian Trail Conference}

The Appalachian Trail Conference is a private, nonprofit organization dedicated to maintenance of the AT, which runs from Georgia to Maine. Seventy miles of the AT run through the Smokies. Over 60 volunteer trail clubs are represented by this group, which conducts research and publishes information on the AT. ${ }^{39}$

\subsection{State Agencies in Tennessee and North Carolina}

\subsubsection{Tennessee Department of Transportation}

TDOT's mission is to plan, implement, maintain, and manage an integrated transportation system for the movement of people and products, with an emphasis on quality, safety, efficiency, and the environment. Organized under the umbrella of TDOT, the Public Transportation, Waterways, and Rail Division is responsible for the following three offices:

- Office of Public Transportation (OPT),

- Office of Rail and Water Transportation, and

- Office of Rail Safety.

\footnotetext{
${ }^{36}$ National Trust for Historic Preservation, “About the National Trust,” http://www.nthp.org/about_the_trust/index.html?cat=6 .

${ }^{37}$ National Trust for Historic Preservation, "State and Local Partnerships," http://nthp.org/state_and_local/activities/2002/tennessee.html .

38 "Experience Your America: Welcome to the Home of the National Park Foundation," http://www.NationalParks.org/index.html

${ }^{39}$ American Park Network, Great Smoky Mountains National Park, $9^{\text {th }}$ Ed., 2000, p. 17.
} 
The OPT provides financial assistance for the operation of 23 public transit systems serving all counties in the State. The services provided by Tennessee's transit systems vary depending on the specific needs of the community and include rail, fixed route bus, demand-response minivan or van, and trolley. OPT provides funding for two specialized trolley systems that serve the recreational areas of Pigeon Forge and Gatlinburg (Section 4.1).

TDOT is interested in applying advanced technologies and innovative management strategies to improve transit operations. For example, the ETVI ${ }^{40}$ in coordination with TDOT and the FHWA, demonstrated an electric bus in each of the Tennessee cities that receive funding from TDOT. The project differed from other demonstrations in that the electric bus was assigned to the local transit system for a period of 5-6 days. The transit system's personnel were responsible for driving and maintaining the electric bus during the demonstration as well as developing a schedule of activities for the vehicle. The electric bus has been demonstrated in both Pigeon Forge and Gatlinburg.

Within TDOT's 2000 Strategic Plan, ${ }^{41}$ several objectives are related to improving transit operations:

- Modify major congested spots to improve traffic flow on Interstates, major urban routes in metropolitan areas, and high tourist impact areas,

- Utilize ITS technology to increase urban interstate capacity and improve transit system efficiency, and

- Improve public transit services in Tennessee, in urban and rural areas.

Within TDOT's 2002-2003 Strategic Plan ${ }^{42}$ objectives are stated more generally without specifying "high tourist "and "transit" areas:

- Improve traffic flow by identifying and modifying congested locations, and

- Improve traffic flow and safety by constructing and operating ITS technologies.

Within the 2002 Intelligent Transportation Systems Strategic Plan, ${ }^{43}$ TDOT assumes a support role in incorporating the following ITS technologies into existing Tennessee public transportation operations:

- Public transportation management to automate operations, planning, and management functions of public transit systems. These plans include (1) providing computer analysis of real-time vehicle and facility status to improve transit operations and maintenance, and (2) integrating this service with traffic control services to help maintain transportation schedules and assure transfer connections in intermodal transportation.

- Enroute transit information to provide travelers with real-time transit information allowing travel alternatives to be chosen once the traveler is in route. These include (1) integrating information from different transit modes and presenting it to travelers for decision-making, and (2) including notification of imminent transit arrival, identification of route of arriving

\footnotetext{
${ }^{40}$ More information concerning the Electric Transit Vehicle Institute can be found at http://www.etvi.org/ .

${ }^{41}$ Tennessee Department of Transportation, TDOT Strategic Plan, March, 2000,

http://www.tdot.state.tn.us/chief_of_administration/Strategic_planning_office/2000_Strategic_Plan/strategic_plan.htm.

${ }^{42}$ Tennessee Department of Transportation's 2002-2003 Strategic Plan, Office of Strategic Planning, March, 2002, http://www.tdot.state.tn.us/chief_of_administration/Strategic_planning_office/2002_Strategic_Plan/strategic_plan.htm .

${ }^{43}$ Tennessee Department of Transportation. Intelligent Transportation Systems Strategic Plan Annual Report, November, 2001, http://www.tdot.state.tn.us/chief_of_administration/Strategic_planning_office/itsplan.pdf .
} 
transit vehicle, schedule, actual service provided, and next available vehicle based on actual operating conditions.

- Personalized public transit to provide flexibly routed transit vehicles (paratransit) to offer more convenient customer service. This includes small publicly or privately owned vehicles providing on-demand routing to pick up passengers who have requested service and deliver them to their destinations.

TDOT recognizes the impact of transportation facilities on the natural, physical, and social environment and provides quality engineering in an environmentally sound manner in the planning, location, design, construction, and maintenance of transportation facilities. In so doing, the Department complies with all applicable Federal and State environmental rules, laws, regulations, and procedures. Emphasis is given to preserve and enhance the existing landscape, environment, and associated wildlife through balanced engineering, environmental, and economic principles.

\subsubsection{Tennessee Department of Tourist Development}

The Tennessee Department of Tourist Development is one of the leaders among State organizations in the United States tourism industry. Tennessee's \$9.7-billion/year tourism industry, drawing nearly 36 million visitors in 2000, is a major economic factor for a majority of Tennessee's 95 counties.

Based on the Tennessee Governor's The Sundquist Administration 1998 Annual Report, every dollar the State invests in tourism promotion returns \$13 in revenue. Based on The Economic Impact of Travel on Tennessee Counties 2000, the public transportation industry posted the largest payroll generated by travel, spending at nearly $\$ 2.4$ billion, $54.7 \%$ of the State total, in 2000. This represents a $7.2 \%$ increase over 1999 .

The GSMNP is the top destination for tourists in eastern Tennessee and the Tennessee State Government feels a responsibility to ensure that all tourists have enjoyable and positive memorable experiences during their visits to the Smokies and its gateway communities.

\subsubsection{Tennessee Department of Environment and Conservation}

One of the major concerns for the Tennessee Department of Environment Conservation is the air quality in the Smokies. In 1997, the State of Tennessee, the National Park Service, and the U.S. Forest Service entered into a cooperative agreement to protect the air quality of the GSMNP. The agreement, also ratified by the Tennessee Air Pollution Control Board, better defines permitting procedures for industries desiring to locate near the Park. Both State and Federal governments issue permits for the construction of new or modified major air pollution sources, and the procedures help coordinate the issuance of these permits.

The procedures are designed to notify Federal land managers about potentially large air emission sources early in the permitting process. They also provide industry with a predictable, welldefined path to follow when applying for air quality permits. In addition to agreeing to the permitting procedures, the participants are committed to expanding cooperation in protecting the resources of Class I areas. This includes pursuing opportunities for exchanging and sharing 
research, information, and personnel to further enhance protection of our nation's valuable natural resources. The agreement also encourages participation in educational conferences and other forums addressing these issues.

\subsubsection{Tennessee Historical Commission}

The mission of the Tennessee Historical Commission is to encourage the inclusive diverse study of Tennessee's history for the benefit of future generations; to protect, preserve, interpret, operate, maintain, and administer historic sites; to mark important locations, persons, and events in Tennessee history; to assist in worthy publication projects; to review, comment on, and identify projects that will potentially impact State-owned and non-State-owned historic properties; to locate, identify, record, and nominate to the National Register of Historic Places all properties which meet National Register criteria; and to implement other programs of the National Historic Preservation Act of 1966 as amended.

\subsubsection{East Tennessee Human Resource Agency}

The objective of the ETHRA (Section 4.1.1) is to strengthen the quality of life of families and communities in the eastern Tennessee area by providing a range of services for individuals - from infants and children to senior citizens. Transportation vans from the agency enable people to be consumers and get medical care such as dialysis. However, recreation trips to the Smokies are not currently served by the agency.

\subsubsection{State Legislators in Tennessee}

In general, the functions of the Legislature are to enact, amend, and repeal the laws of Tennessee. Some of the specific powers granted to the General Assembly by the State Constitution include the appropriation of all money to be paid out of the State treasury, the levying and collection of taxes, and the right to authorize counties and incorporated towns to levy taxes.

Legislative proposals can originate in either the Senate or House in the form of bills, resolutions, and joint resolutions. A bill is a proposed law and may be either general or local. A general bill has a Statewide impact, and a local bill affects only a particular county or town named in the bill. This local bill is sometimes referred to as "enabling legislation." If the local bill passes the legislature, then it must be ratified by the local governing body or voted on by the people of that area.

The State legislature is elected by the people of Tennessee. Therefore, State legislators will be interested in subjects that the people in Tennessee are interested in. It should be noted that Tennessee has no income tax. The sales tax is the major source $(55 \%)$ of all State expenditures. Together with the fact that tourism is the second largest industry for the State, it is not difficult to understand the State Legislators' interests in the well-being of the Smokies. 


\subsubsection{North Carolina Department of Transportation}

NCDOT's mission is to provide and support a safe and integrated transportation system for the State. NCDOT fulfills this mission through two major thrusts. First, NCDOT directs, plans, constructs, maintains and operates the second largest State-maintained transportation system in the nation, including aviation, ferry, public transportation, rail, and highway systems. Second, NCDOT licenses and regulates the citizens and motor vehicles that utilize these transportation systems.

The NCDOT Public Transportation Division helps North Carolina public transit systems move people. The mission of this division is to help foster the development of intercity, intracity, and rural public transportation in the State and administer Federal and State transit grant programs. Although the division doesn't operate buses, trains, or vans directly, which is the responsibility of local transit systems, the division helps them operate safer and more effectively.

More than 100 urban and rural public transportation systems serve millions of North Carolinians in all 100 North Carolina counties. By combining the division's resources with local communities and transportation providers, the division helps make public transit in North Carolina more efficient.

As population and travel demand in North Carolina continue to grow - at an estimated rate for 1998 that is more than $30 \%$ faster than the rest of the nation - the availability of good transportation is one of the most critical challenges the State faces for the 21st century. Meeting this challenge requires an effective balance among highways, bus and rail transit, community transportation services, ferries and intercity passenger trains. Safe, efficient, and effective public transportation is crucial for this goal and critical to continuing North Carolina's economic growth and prosperity, preserving the State's way of life and protecting the character of its communities.

Each of the North Carolina regions has prepared an ITS strategic planning document. Based on the regional plan for the western part of the State, ${ }^{44}$ the NCDOT has both short-term and long-term transit-related projects for that area. Short-term proposed transit ITS projects include transit dispatching, demand forecasting, and automatic passenger counting. A computer-aided dispatching system will be developed and deployed for four transit systems in the region. These individual projects will include an automatic passenger counting system that works in concert with an automated vehicle location system to obtain data for future route planning purposes. Long-term transit ITS projects involve smart card payment systems. Numerous regional bus systems either exist or are planned within the region. For these systems, a regional electronic payment system will permit the same method of payment for all transit systems within the region. In addition to enabling travelers to use multiple bus systems without a complicated payment system, smart cards allow the various transit and planning agencies to better track ridership, transfers, and other information that can be collected in the planning for future transit enhancements.

One rural ITS application directly related to the Smokies was a Highway Advisory Radio at the intersection of U.S. Highway 74 and Interstate-40 in Haywood County. This radio was used to provide information about the closing of U.S. Highway 441 in the Park during maintenance work

\footnotetext{
${ }^{44}$ North Carolina Smartlink, North Carolina Statewise Intelligent Transportation System Strategic Deployment Plan: Western Regional Plan, http://www.ncsmartlink.org/strategic/default.htm.
} 
on the tunnels. In addition, information concerning the construction work was provided on the statewide traveler information website ( http://www.ncsmartlink.org/ ). ${ }^{45}$

\subsubsection{North Carolina Division of Tourism, Film and Sports Development}

The Division of Tourism, Film and Sports Development is part of the North Carolina Department of Commerce. The goal of this Division is to strengthen the State's tourism, film and sports industries to enhance the economic well being and quality of life for all North Carolinians. Tourism has grown into one of the State's largest industries. Annually, more than 43 million people visit North Carolina and spend \$12 billion. Domestic tourism in Haywood County, Graham County, and Swain County generated an economic impact of \$165.42 million in 2001, which amounts to approximately $1.4 \%$ of the State total economic impact of $\$ 11,911.59$ million. The Blue Ridge Parkway and the GSMNP are the top tourist attractions.

\subsubsection{North Carolina Department of Environment and Natural Resources}

The North Carolina Department of Environment and Natural Resources (DENR) is the lead stewardship agency for the preservation and protection of North Carolina's outstanding natural resources. The organization, which has offices from the mountains to the coast, administers regulatory programs designed to protect air quality, water quality, and the public's health. Recent legislation requires North Carolina power plants to reduce pollution. DENR also offers technical assistance to businesses, farmers, local governments, and the public and encourages responsible behavior with respect to the environment through education programs provided at DENR facilities and through the State's school system. Through its natural resource divisions, DENR works to protect fish, wildlife, and wilderness areas. The agency's activities range from ensuring safe drinking water to managing State Parks and forests for safe and enjoyable outdoor recreation experiences.

\subsubsection{North Carolina State Historic Preservation Office}

The North Carolina State Historic Preservation Office assists private citizens, private institutions, local governments, and agencies of State and Federal governments in the identification, evaluation, protection, and enhancement of properties significant in North Carolina history and archaeology. The agency carries out State and Federal preservation programs and is a component of the Office of Archives and History, North Carolina Department of Cultural Resources. The office serves as the staff of the State Historic Preservation Officer, who is the Deputy Secretary for the Office of Archives and History, and as staff of the North Carolina Historical Commission in the review of State and Federal development projects that might affect historic North Carolina properties.

\subsubsection{State Legislators in North Carolina}

The legislative branch is composed of the General Assembly and its administrative support units. The Constitution of North Carolina gives the General Assembly the authority to make or enact laws; to establish rules and regulations governing the conduct of the people, their rights, duties and procedures; and to prescribe the consequences of certain activities. The General Assembly has the

\footnotetext{
${ }^{45}$ Moore, Reuben, Personal communication with Tykey Truett, May 13, 2002. 
power to make new laws and amend or repeal existing laws that affect all the people of the State as well as laws affecting the local communities. The General Assembly of North Carolina is made up of two houses - the House of Representatives and the Senate. Members of the General Assembly are elected by voters from their respective districts.

\subsection{Regional Agencies and Gateway Communities}

\subsubsection{Knoxville Regional Transportation Planning Organization}

The Knoxville Regional Transportation Planning Organization (TPO) has taken an active role in planning for transportation needs in the East Tennessee area. Through public meetings and independent studies, the TPO developed an assessment of alternative transportation options for ten counties in the East Tennessee area. The Regional Transportation Alternatives Plan (RTAP) was a broad planning effort that eventually focused on a five-county area - Knox, Anderson, and Loudon counties in addition to the two counties (Blount and Sevier) which adjoin the Park boundaries. This regional approach to planning was coordinated through the Regional Transportation Alternatives Committee (RTAC). The RTAP study is now complete. For the corridor in Sevier County beginning at the intersection of I-40 and TN-66 and continuing to Gatlinburg, Tennessee, via Sevierville and Pigeon Forge (24 miles), the study recommended Bus Rapid Transit (BRT). Cost estimates for development of the BRT total \$53 million; annual operating costs are estimated at $\$ 2.5$ million. This recommendation, including types of vehicles and roadways and other service requirements are more fully documented in Chapter 6 of the RTAP Final Report. ${ }^{46}$

Specifically related to the GSMNP, a technology assessment report was prepared for the Cades Cove area. ${ }^{47}$ The report assessed various types of transit for Cades Cove based on visitor demand, visitor experience, resources, infrastructure requirements, and operational issues. Potential fatal flaws and major issues to be resolved were identified. The report is available on the TPO website, www.knoxtrans.org.

In an effort to preserve and protect Cades Cove, the National Park Service and TPO are working on a development concept and transportation management plan (commonly known as the Cades Cove Opportunities Plan). When completed, the Plan will provide a comprehensive, long-range approach to managing the Cove's natural and cultural resources and improving the quality of the visitor experience. Public meetings began in May 2002. Problem statements, goals, and objectives and options for addressing the problems have all been discussed. Up to four draft alternatives will be built based on options heard from the public and screening criteria. The public will review these alternatives in early 2003.The initial phase of the Plan will be completed by Summer 2003, followed by an Environmental Impact Statement process.

A grant of \$70,000 from Ford Motor Company was provided through the National Park Foundation to be used in concert with the Cades Cove Opportunties Plan. The grant will be used for gateway

\footnotetext{
${ }^{46}$ Wilbur Smith Associates, Regional Transportation Alternatives Plan (RTAP) for East Tennessee, Final Report, prepared for Mr. Jeff Welch, Knoxville Regional Transportation Planning Organization, Knoxville, Tennessee, March 2002.

${ }^{47}$ Cades Cove Technology Assessment Report, produced for the Regional Transportation Alternatives Committee, Knoxville, Tennessee, http://www.knoxtrans.org/rtap/cadescovereport.htm, August 2001.
} 
community planning "to help develop innovative transportation and environmental solutions". 48 Townsend and Tuckaleechee Cove will be the areas most affected by any changes to the management of Cades Cove. This planning process will develop strategies that the community can use to address the potential impacts on Townsend and Tuckaleechee Cove resulting from the alternatives being developed through the Cades Cove Opportunities Plan.

\subsubsection{Nine Counties/One Vision}

The purpose of the Nine Counties/One Vision organization is to develop a vision for the East Tennessee area through consensus building. Meetings were held to determine goals and objectives to help the region plan for the future. Eleven categories were designated for improvement. One of the categories was transportation. The goal for transportation in the area was to develop a regionwide bus transportation system that would be "rapid, affordable, reliable, environmentally friendly, safe, economic, and efficient." The purpose was "to fully enjoy the region's social and cultural amenities and ... minimize the use of personal vehicles." ${ }^{.9}$ Although the organization goals for transportation do not specifically mention the GSMNP, there is an implicit understanding that the Park is a valuable cultural resource.

\subsubsection{Highway Patrol and Other Incident Response Agencies}

Because the GSMNP spans two States and multiple jurisdictions, responsibilities for incidents is sometimes difficult to assign. Generally, if an incident occurs on a State highway, the State Highway Patrol will be in charge of the accident report. If the incident is on a roadway other than a State highway, the local police will be responsible. Emergency personnel, if needed, will be dispatched based on which local entity is in charge (usually a county).

In the Smokies, however, the NPS, specifically the Park Rangers, have jurisdiction in the Park. The highway between Gatlinburg and Pigeon Forge, Tennessee, is considered a joint jurisdiction between the Park and the Tennessee Highway Patrol. The Park Service provides crash reports on fatalities to TDOT; the NPS maintains a database on non-fatal crashes that occur within the Park boundaries. ${ }^{50}$

Occasionally, small planes will crash in the Smokies. Emergency search and rescue personnel affiliated with Park services are usually first on the scene and Federal investigators will be responsible for trying to determine the cause of the crash.

\subsubsection{County and Community Planning Commissions, Elected Officials, Chambers of Commerce, Departments of Tourism, and Visitor Bureaus}

The elected officials, committees, commissions, and departments of the regional agencies and gateway communities are critical in any plan for the Smokies. In addition, tourism is extremely important to the economic well-being of the communities. Therefore, community involvement must

\footnotetext{
48 “The National Park Foundation and Ford Motor Company Support Transportation Study in Smokies," KnoxNews, http://www.knoxnews.com/kns/inside_the_park/article/0,1406,KNS_391_1089046,00.html, April 17, 2002.

${ }^{49}$ Nine Counties/One Vision, "Transportation Goals \& Strategies,” http://www.ninecountiesonevision.org/html/transportation.html.

${ }^{50}$ Valentine, Clinton, Personal e-mail conversation with Tykey Truett, May 2, 2001.
} 
be part of the decision-making process. As noted in other sections, these agencies and organizations are being considered and integrated by the NPS in planning efforts. Unfortunately, communication at various levels to local agencies and to individuals within the communities is not always successful. ${ }^{51}$

More information about the gateway communities surrounding the GSMNP is available from links on the Park's website. ${ }^{52}$

\subsubsection{Eastern Band of the Cherokee Nation}

The Cherokee Indian Reservation, located adjacent to the GSMNP in western North Carolina, is home to 12,500 enrolled members of the Eastern Band of the Cherokees. Many tourist attractions are located near the town of Cherokee, North Carolina, including museums, native arts and crafts demonstrations and shops, an outdoor drama depicting the Trail of Tears, amusement parks, recreational opportunities, zoos, gift shops, and tours. Tribal bingo and other gaming attractions are provided by Harrah's Casino. ${ }^{53}$

\subsubsection{East Tennessee Economic Development Agency}

The East Tennessee Economic Development Agency, headquartered in Knoxville, Tennessee, is a regional partnership providing site selection services to businesses in the Knoxville-Oak RidgeSmoky Mountains region. It offers labor and training, utility services, community information, and transportation services, as well as real estate assistance, site location planning, and construction information.

\subsubsection{Land-of-Sky Regional Council}

The Land-of-Sky Regional Council is a planning and development organization representing four counties (Buncombe, Henderson, Madison, Transylvania) and 14 municipalities in North Carolina. ${ }^{54}$ Members meet monthly. The Council, which began in 1966, is funded through Federal, State, and local government funds and some private funds. This organization has a mission to foster desirable conditions in the four counties it represents; however, it is not directly related to transportation issues within the Smokies.

\footnotetext{
${ }^{51}$ An overflow crowd appeared at a Townsend, Tennessee, City Commission meeting in April 2002 to protest the building of a parking lot in front of a local business with State DOT monies. For more information, see "State Official Says Parking Lot in Townsend Will Be Built," The Daily Times, April 17, 2002, pp. 1A, 6A.

${ }^{52}$ National Park Service, "Great Smoky Mountains National Park, Area Communities," http://www.nps.gov/grsm/gsmsite/areacomm.html .

${ }^{53}$ Cherokee Indian Reservation, http://www.Cherokee-nc.com/main.htm .

${ }^{54}$ Land-of-Sky Regional Council, "Transportation," http://www.landofsky.org/transportation/ .
} 


\subsection{Business and Commercial}

\subsubsection{Transit Operators and Providers}

Transit operators and providers in the area immediately surrounding the GSMNP are limited. These providers are described in Chapter 4. Only one transit service advertises tours that actually enter the Park boundaries, and this is a limited tour from Gatlinburg (see Section 4.1.3). There is no transit service available to tourists who wish to visit Cades Cove, which is actually the most frequent site visited within the Park. In addition, no transit service crosses the Park between Tennessee and North Carolina. There is no transit mechanism in place to provide daily access to jobs within or on opposite sides of the Park.

There is very little interaction among the transit providers. The transit operations do not have overlapping coverage or cooperative agreements.

\subsubsection{Tourist Attractions}

The gateway communities host a myriad of entertainment venues. Lodging, restaurants, and tourist attractions provide a major source of income for the local residents and business owners. Although there are many attractions, a few of the larger businesses deserve special mention. These include Dollywood (Pigeon Forge, Tennessee), Harrah's Casino (Cherokee, North Carolina), and Ghost Town in the Sky (Maggie Valley, North Carolina). In addition, during the summer there are numerous special events, such as street rod festivals.

The population of the gateway communities fluctuates with the seasons. For example, the population of Pigeon Forge goes from a very low winter population to a very high summer population because of the influx of tourists.

Involving the 511 initiative for provision of traveler information would be an excellent way to "advertise" the tourist attractions in the area, as well as the transit option, when developed.

\subsubsection{Media Producers}

Involving the media is critical to the success of a venture that involves the health and mobility of such a large number of people. Television stations, radio stations, and newpapers abound in the East Tennessee and Western North Carolina areas bounding the Park. In addition, various web sites promote the tourism industry.

\subsubsection{Other Business and Commercial Interests}

Many other commercial interests are interested in and could assist with development of a solution to the Park's transportation woes that will accommodate the vision of the gateway communities. A good example is the Ford Motor Company's involvement with the National Park Foundation, which recently supplied a $\$ 70,000$ grant (see Section 5.3.1). 


\subsection{Community Interest/Political Action Groups}

\subsubsection{Southern Appalachian Mountain Initiative}

The Southern Appalachian Mountain Initiative (SAMI) was a consortium of various groups from eight States (Alabama, Georgia, Kentucky, North Carolina, South Carolina, Tennessee, Virginia, and West Virginia). This 10-year partnership, initiated in 1992, included State and Federal environmental regulatory agencies, Federal land managers, industry, academia, environmental groups, and interested public participants. The primary focus was on the impacts of ozone, regional haze, and acid deposition in the Southern Appalachian Mountains. SAMI provided a forum for environmental, economic, regulatory, public, and private interests to meet and work together rather than in an adversarial relationship. In late 2002, SAMI completed an integrated assessment to characterize new and existing Federal Clean Air requirements. ${ }^{55,56}$

\subsubsection{Friends of the Great Smoky Mountains National Park}

This organization, which began in 1993, is a nonprofit, tax-exempt foundation with goals of assisting as needed with Park projects (e.g., raising funds, enhancing public awareness, providing volunteers). Friends of the Smokies headquarters is in Sevierville, Tennessee; the North Carolina Office is in Waynesville. Since its foundation, the group has raised over $\$ 8$ million. Under a Memorandum of Agreement with the NPS, projects are chosen from an annual needs list compiled by the Park. ${ }^{57}$

\subsubsection{Great Smoky Mountains Natural History Association}

This nonprofit group was founded in 1953. It publishes the Park newspaper and other articles, funds library positions, prepares demonstrations and displays, and operates the Great Smoky Mountains Institute at Tremont. The association headquarters is in Gatlinburg, Tennessee. ${ }^{58}$

\subsubsection{Foothills Land Conservancy}

Founded in 1985, the Foothills Land Conservancy is an independent, nonprofit land trust with a goal to preserve natural resources of East Tennessee. Over time the organization has purchased over 6,200 acres of land, which has then been transferred to the NPS (400 acres) or the Tennessee Wildlife Resources Agency.

\subsubsection{Cades Cove Preservation Association}

The Cades Cove Preservation Association, established in January 2001, is a nonprofit organization registered in Tennessee. The purpose of the group is to preserve the heritage of the families who lived in Cades Cove. This group has partnered with the Friends of the Great Smoky

\footnotetext{
${ }^{55}$ Southern Appalachian Mountains Initiative, "SAMI," http://www.saminet.org/ and associated links.

${ }^{56}$ Southern Appalachian Mountains Initiative, SAMI: Southern Appalachian Mountains Initiative, Final Report, August 2002.

${ }^{57}$ Friends of Great Smoky Mountains National Park, "Friends of the Smokies," http://www.friendsofthesmokies.org.

${ }^{58}$ American Park Network, Great Smoky Mountains National Park, $9^{\text {th }}$ Ed., 2000, p. 17.
} 
Mountains to work with the GSMNP to maintain and preserve the historical structures and cemeteries of the Cove.

\subsubsection{Hiking Clubs}

Three hiking clubs are active in the East Tennessee area - the Smoky Mountains Hiking Club (SMHC), the Foothills Striders, and the Knoxville Track Club.

The SMHC, with over 600 members, is a recreational club dedicated to hiking. One of the goals of the club is preservation of natural resources. The club was formed in 1924 and has, through the years, played a significant role in blocking road construction projects. The club is currently focusing on the following conservation issues in the Smokies:

- Proposed new road from Bryson City to Fontana Dam,

- Proposed trade of GSMNP land inside the Park for Cherokee Indian Reservation land outside the Park,

- Widening of U.S. 321 and development of land immediately adjacent to the Smokies,

- Removal of cottages at Elkmont campground. ${ }^{59}$

A subgroup of the SMHC is the Appalachian Trail Maintainer Committee. This group works in partnership with the Appalachian Trail Conference, NPS, Forest Service, and other organizations to manage and maintain the 70 miles of the AT that are within the Smokies. ${ }^{60}$

The Foothills Striders, a local, nonprofit organization established over 20 years ago, has about 170 members in all age groups. The club meets monthly and promotes various outdoor activities, including community service activities.

The Knoxville Track Club is primarily a recreational club promoting competitive running events. Some of the events have been in the Smoky Mountains. Many of the events raise monies for worthy causes.

\subsubsection{Horseback Riders}

Equestrians enjoy the trails in the Smokies. Horses may be rented from private stables located in the Park. The Park also has five drive-in horse camps - four in North Carolina and one in Tennessee. ${ }^{61}$ Two Tennessee equestrian groups are particularly involved with trails in the Smokies - the Smoky Mountain Trail Riders and the Blue Ridge Trail Riders. Both of these groups are involved with trail maintenance. The charter of the Blue Ridge Trail Riders includes three points dealing with public lands management. ${ }^{62}$

\footnotetext{
${ }^{59}$ Smoky Mountains Hiking Club, "Wilderness Advocacy and the Smoky Mountains Hiking Club," http://www.esper.com/smhc/wa/index.htm .

${ }^{60}$ Appalachian Trail Maintainer Committee, Smoky Mountain Hiking Club, "Appalachian Trail Maintainer News, 2001," http://www.esper.com/smhc/atnews.htm.

${ }^{61}$ American Park Network, Great Smoky Mountains National Park, $9^{\text {th }}$ Ed., 2000, p. 50.

${ }^{62}$ Blue Ridge Trail Riders, "About Us," http://blueridgetrailriders.com.
} 


\subsubsection{Bicycling, Hiking, Camping, and Fishing Interests}

Bicycling is permitted throughout the Park on paved roads, but is prohibited on trails. Because even the paved roads are narrow and sometimes very congested, however, they are not always safe or pleasant for bike riders. Cataloochee Valley and the 11-mile loop at Cades Cove are closed to automobile traffic on Wednesday and Saturday until 10 a.m. from spring through midSeptember and become pleasurable routes for both bike riders and hikers. There are bike concessionaires located at the Cades Cove Campground store. There are many hiking trails with superb views. Finally, there are over 1,000 developed campsites at ten campgrounds and 100 primitive backcountry campsites. The Park is home for over 80 species of fish; however, the clear mountain streams are best known for trout. The Great Smoky Mountains Chapter of Trout Unlimited has almost 400 members. They meet once a month and partner with local businesses (e.g., TVA) to clean up rivers and river banks. Many individuals who participate in the recreational activities noted above belong to one or more of the public-interest groups discussed in this report.

\subsubsection{Mountain Air Quality Coalition}

This coalition has several goals concerning air quality issues in the mountainous counties of western North Carolina. The primary aim is to raise public awareness of ground-level ozone, haze, and acid deposition. Three specific goals that are related to the Smokies are to (1) reduce mobile source emissions (i.e., promote less driving), (2) inform the public concerning alternative transportation programs and options, and (3) promote alternative fuels and vehicles. ${ }^{63}$

\subsubsection{Canary Coalition}

The Canary Coalition, headquartered in Whittier, North Carolina, is a nonprofit organization with a clean-air message. The group coordinates public events to advertise air quality issues and to influence policy makers. The group is concerned about the status of pollution in the Smokies but is primarily targeting coal-fired power plant emissions as the guilty culprit, rather than excessive automobile exhausts. ${ }^{64}$

\subsubsection{Western North Carolina Tomorrow}

This 18-year-old organization is a nonprofit citizen organization solving regional and community problems of 17 westernmost counties of North Carolina through collaboration. The group's mission is to provide an opportunity for individuals and organizations to work together to examine problems, plan for the future, and gain leadership experience. The Mountain Air Quality Coalition is affiliated with this group. ${ }^{65}$

\footnotetext{
${ }^{63}$ Goldberg, Andrew, "Mountain Air Quality Coalition,” http://www.wnct.org/maqc1.html .

${ }^{64}$ The Canary Coalition, "The Canary Coalition, a Grassroots Clean Air Movement," http://www.canarycoalition.org .

${ }^{65}$ Western North Carolina Tomorrow, "The Voice of the Mountain Region," http://wnct.org .
} 


\subsubsection{Visibility Improvement State and Tribal Association of the Southeast}

Visibility Improvement State and Tribal Association of the Southeast (VISTAS), which is a coalition of state governments, tribal governments, and other agencies, was established to coordinate activities for managing visibility issues. 


\section{STRATEGIC APPROACHES FOR A SMOKIES SOLUTION}

With such a large area, which involves two States, multiple jurisdictional entities, scores of different interest groups, and technical difficulties, coordination of potential solutions to the transportation issues in the Smokies will necessitate great planning and skill. Some of the challenges and barriers to development of a coordinated approach to the entire Park are discussed below. The benefits of using an ITS transit approach to solve the challenges are then described. Finally, strategic approaches to obtaining agreement and cooperation of all of the interested parties and a timetable are provided.

\subsection{Challenges and Barriers}

A recent study identified barriers to successful implementation of transit in National Parks. These barriers included technical challenges, lack of coordination with and support of gateway communities, a lack of a dedicated funding source, and inadequate marketing to the public. Although FHWA and FTA provide some assistance for planning, design, construction, and procurement of transit systems, they provide very limited financial support for the implementation of transit systems. ${ }^{66}$

\subsubsection{Infrastructure Limitations}

Because a tenet of the NPS is to "lie lightly on the land," the option for building additional roadway within the GSMNP to alleviate the traffic problems is simply not a feasible solution. By the same token, any transit solution must consider this same limitation.

Because of the topography of the mountainous terrain, some transit options that might be considered in other localities are infeasible along certain routes in the Smokies. Furthermore, traffic counts vary considerably at the different sites and according to the season. A single size and/or type of transit will almost certainly fail to meet infrastructure and passenger needs for the entire Park.

Another major limitation is the almost total lack of existing telecommunications infrastructure in the Park. In its traditional form, telecommunications infrastructure can be very expensive, one of the most expensive costs in an ITS implementation. In addition, because of rapid changes in technology and because of multiple jurisdictional issues, the telecommunications problem is a serious limitation. ${ }^{67}$

\subsubsection{Environmental Concerns}

If a transit system within the Park involves construction (parking areas, roads, rails, trolley lines, etc.), various environmental concerns must be addressed. These include, for example, drainage patterns, stream stability, stream crossings, erosion on steep slopes, potential archaeological or

\footnotetext{
${ }^{66}$ Federal Highway Administration and Federal Transit Administration, Federal Lands Alternative Transportation Systems (ATS) Study, Program Development, August 2001, http://www.fta.dot.gov/library/policy/fedland/v4/exsum.pdf .

${ }^{67}$ Federal Highway Administration and Federal Transit Administration, Communications for Intelligent Transportation Systems: Successful Practices, FHWA-JPO-99-023; FTA-TRI-11-00-02, November 2000.
} 
cultural sites, threatened or endangered species, and wetlands. The Cades Cove study described in Section 5.3.1 may ascertain that an Environment Impact Statement is required prior to any construction activity that might be required.

Generally speaking, the introduction of a mass transit system could only improve the environmental conditions. Many air quality problems in the Smokies are exacerbated by the exhaust fumes from automobiles, especially during October, when traffic is "bumper to bumper."

About 50 National Park units have visitor transportation systems of some type; about 30 systems are surface-based (as opposed to air- or water-based). Of these 30 systems, about six use alternative-fueled vehicles, including propane, compressed natural gas, and electricity. ${ }^{68}$

\subsubsection{Political Issues Involving Coordination}

A barrier to establishment of an alternative transportation system in the Smokies will be the coordination of the various stakeholders. When a wide range of Federal, State, and local organizations have control of varied portions of the system, the user is the loser. As noted in Section 4, there is no coordination among the existing trolley systems operated in gateway communities whose city limits practically touch.

To lay groundwork for success, the following questions must be answered:

1. How fragmented is the responsibility for transportation and community development ...?

2. Are the mission and goals of public transportation organizations consistent with ... broader strategies and goals?

3. Who is responsible or accountable for the long-term consequences of transit and transportation investment ...?

4. What public policies, regulations, decision-making processes, or attitudes stand in the way of more effective arrangements? ${ }^{69}$

The transportation system must allow riders to choose the services they desire and must not force them to select among competing services.

Finally, coordination must include negotiations with the Eastern Band of the Cherokee Indians whose tribal lands are adjacent to the Park.

\footnotetext{
${ }^{68}$ Cades Cove Technology Assessment Report, August 2001, pp. 4-1 and 4-3.

${ }^{69}$ Transportation Research Board, National Research Council, New Paradigms for Local Public Transportation Organizations, TCRP Report 58, National Academy Press, Washington, D.C., 2000, p. 11.
} 


\subsubsection{Financial Issues}

Public transit was, until the late 1940s, operated on a for-profit basis by private companies. However, better highways, faster automobiles, the move to suburbia, and the inability of transit services to adapt to the changing needs forced a change in ownership. Public ownership with subsidies is the current model. ${ }^{70}$

Financing a transit system where none now exists (except for the limited trolley service from Gatlinburg into the Park; see Section 4.1.3) will be a challenge. In addition, there is no clear jurisdictional responsibility. Providing for a consistent fare system and a seamless transfer between modes or jurisdictions will be critical to ensure success.

\subsubsection{Data and Information Needs}

Many studies have been conducted within the Park. In addition, the Cades Cove area is currently being extensively studied in order to arrive at options to address the transportation issues. Additional information in the following areas would be useful to supplement the current information base:

- Potential ridership counts for various sites and times of year within the Park,

- Types of services desired by the potential ridership (For example, should a transit system be capable of hauling recreational equipment such as bikes or camping gear? Would rapid transit be appropriate for some corridors within the Park or adjacent gateway communities? Are observation decks a desirable feature?),

- Carrying and parking capacity of various areas,

- Endangered species and critical archeological sites,

- Safety issues (For example, what types of resources are appropriate/available for various types of emergencies?),

- Jurisdictional responsibilities, etc.

The Transportation Research Board (TRB) recognizes the difficulty in a one-shoe-fits-all approach for transit applications within the National Parks. Every Park has unique features and needs. While the GSMNP is not an urban Park, it has many problems, such as air pollution, which are associated with urban areas. TRB has identified the following research topics related to transportation issues in National Parks:

- Developing more sophisticate planning models for estimating visitor travel demands,

- Exploring advanced technologies to enhance pre-trip and in-route information,

- Documenting experience with buses that use alternative fuel,

- Exploring institutional issues and arrangements,

- Developing construction materials and techniques for environmentally sensitive areas, and

- Monitoring and evaluating the projects already under way. ${ }^{71}$

\footnotetext{
${ }^{70}$ Transportation Research Board, National Research Council, New Paradigms for Local Public Transportation Organizations, TCRP Report 58, National Academy Press, Washington, D.C., 2000.

${ }^{71}$ Turnbull, Katherine F., "Visitor Transportation at U.S. National Parks; Increasing Accessibility but Preserving the Environment," pp. 3-8 in TR News, September-October 2000.
} 


\subsubsection{Technology Limitations}

Implementing advanced public transit systems such as fleet management systems and traveler information systems rely heavy on advanced electronic sensors and extensive communication networks. As noted in Section 6.1.1, modern roadside telecommunication infrastructure within the Smokies is lacking. For example, there is no existing electricity power supply inside the Park that can power roadside equipment. Very limited telecommunication tower or land-based cable networks exist to support comprehensive communication coverage. Because Park rules and regulations limit the use of powered tools in wilderness areas, new construction to modernize roadside infrastructure (e.g., to build radio towers) would be challenging.

Certain advanced public transit technologies such as automatic vehicle location (AVL) systems require receiving signals from satellites. The hilly terrain and tree canopies of the Smokies might create "blind" areas for AVL systems.

Other demand management technologies such as dynamic ridesharing or automated service coordination might not be suitable for the Smokies. The visitation pattern for the Smokies is typically a private vehicle containing a family traveling together. There are very few single occupant vehicles in the Smokies. Ridesharing or other similar measure will not significantly reduce the existing traffic in the Smokies.

Roadway surfaces within the Smokies vary from paved to gravel. Some roadway segments in the Smokies are constructed according to National Park standards with adequate sight distance and lateral width for passing, but most segments have steep grades and limited sight distance. Therefore, no one type of transit vehicle can be used for all locations inside the Smokies. For example, the one-way road in the Cades Cove area is narrow and twisting but relatively flat. The two-lane Highway 441 from Gatlinburg to Cherokee, however, must overcome steep grades (Figure 2.5) and a circuitous route (Appendix A, Figure A.5).

\subsubsection{Policy Issues}

A clear set of requirements must be documented. In the Park, resource conservation and preservation are fundamental goals. These goals must be considered in conjunction with visitor access.

It is also important to consider the economic impact of Park visitors on the gateway communities. A transit system could help finance its operations with advertisements for local attractions.

Finally, customer services on the transit system and at the parking areas should be designed to be reliable, safe and secure, convenient and accessible, comfortable and clean, understandable, affordable, and empathetic. ${ }^{72}$

\footnotetext{
${ }^{72}$ Transportation Research Board, National Research Council, Management Toolkit for Rural and Small Urban Transportation Systems, TCRP Report 54, National Academy Press, Washington, D.C., 1999, p. 1.3.
} 


\subsubsection{Population Concentration}

The Knoxville Regional TPO (see also Section 5.3.1) has conducted several studies on mass transit feasibility. A regional plan (RTAP) was developed that focused on five East Tennessee counties (Knox, Sevier, Blount, Anderson, and Loudon). This area was selected because it contains major travel corridors that could support some form(s) of mass transit. For these counties, population growth was $23 \%$ between 1980 and 2000 . Slow steady population growth at about $1 \%$ per year is projected through the year 2030. Job growth is at a similar pace. Population concentrations sufficient to support a mass transit system are infrequent in the five-county area and simply do no exist in the gateway communities of Gatlinburg, Pigeon Forge, and Gatlinburg. However, population density does not account for the number of motel rooms and the job opportunities created by the tourist industry in these communities. ${ }^{73}$ RTAP will be considering the Park's gateway communities in its transit planning. The "barrier" to deciding on a form of mass transit for the gateway communities surrounding the Park is simply the lack of a permanent yearround population base.

Within the Park, traffic patterns, both vehicular and pedestrian, are unique. The major thoroughfares within the Park are congested during the peak season. Pedestrian traffic at points of interest (e.g. trail heads, picnic grounds, scenic views, historical places) in the Park is not, however, as crowded. Although one can speculate that the reason for the lower pedestrian traffic is the lack of available parking spaces at these points of interest, it must be noted that a sustainable transit system can only be implemented if there is sufficient ridership utilizing the system. The transit system must enhance the visitor's experience by allowing the rider to view the scenery. The system should also allow the passengers to exit and reboard as desired.

\subsection{Benefits from Use of Rural ITS Transit}

\subsubsection{Infrastructure}

A guiding principle in ITS implementations is documentation of a formal requirements analysis. This definition of requirements will include alternative solutions and a comparative analysis of the alternatives. This analysis will ensure that all requirements are captured, clearly defined, agreed upon, and testable. ${ }^{74}$

When designing a regional ITS architecture, a useful tool is the National ITS Architecture, which is available online or on CD-ROM. This tool provides important guidelines to ensure that all components are considered. It is implementation and technology independent. ${ }^{75}$

\footnotetext{
${ }^{73}$ Knoxville Regional Transportation Planning Organization, Regional Transportation Alternatives, "RTAP Briefing Meetings, June 2001," http://www.knoxtrans.org/rtap/briefingmeetingjune2001.htm .

${ }^{74}$ Federal Highway Administration and Federal Transit Administration, U.S. Department of Transportation, Communications for Intelligent Transportation Systems: Successful Practices, FHWA-JPO-99-023; FTA-TRI-11-00-02, November 2000.

${ }^{75}$ Federal Highway Administration and Federal Transit Administration, U.S. Department of Transportation, Communications for Intelligent Transportation Systems: Successful Practices, FHWA-JPO-99-023; FTA-TRI-11-00-02, November 2000, p. 18
} 
Mode options considered by the RTAP included light rail systems and monorail. One rationale for this choice would be to encourage tourists to leave their automobiles at a parking garage. To be effective, however, a rail system should average 1,000 riders per route mile per day. ${ }^{76}$ At this point in time, this is not a likely alternative.

Another option recommended by the RTAP is Bus Rapid Transit (BRT) for the Interstate 40Sevierville-Pigeon Forge-Gatlinburg corridor. Because both Pigeon Forge and Gatlinburg rely heavily on tourist traffic and because Gatlinburg is a major entrance to the Park, this transit system could alleviate considerable traffic congestion between the two communities. Infrastructure development would be required for busways, bus lanes, or high-occupancy vehicle lanes to ensure that the transit vehicles could bypass traffic congestion. ${ }^{77}$

This option, if implemented, could showcase many ITS technologies such as integrated parking, AVL systems, and passenger counts. Coordination with the Pigeon Forge and Gatlinburg trolleys would be critical to the success of this effort.

Finally, within the Park, the most congested area is the 11-mile Cades Cove loop road. Rural transit options that might be used to alleviate the transportation issues within Cades Cove would almost certainly need to use existing roadway because of the environmental sensitivity of the area. Therefore, this transit would require more "bells and whistles" to be appealing to the public ridership.

\subsubsection{Environment}

Within the Park, ITS technologies not requiring additional roadway infrastructure could address both congestion and air quality issues. For example, if a rural transit system were implemented between the community of Townsend, Tennessee, and Cades Cove, its usage could eliminate a percentage of the automobile traffic on the loop road. Parking facilities at Townsend could be designed with efficiency and safety as critical components. In addition, this potential system could use alternative fuels, which would be another boon to the environment.

\subsubsection{Political Issues}

The coordination of political issues could be the most difficult problem to surmount. If the transportation solutions are built around the current efforts to coordinate public input and build consensus within the communities surrounding the Park, then they will have a greater likelihood of success. Not only tourists, but also residents of the areas surrounding the Park, should provide input concerning desirable features of any proposed transit system.

\footnotetext{
${ }^{76}$ Knoxville Regional Transportation Planning Organization, Regional Transportation Alternatives, "RTAP Briefing Meetings, March 2001," http://www.knoxtrans.org/rtap/briefingmeeting.htm .

${ }^{77}$ Regional Transportation Alternatives Plan (RTAP) for East Tennessee, Final Report, produced by Wilbur Smith Associates for the Regional Transportation Alternatives Committee, Knoxville, Tennessee, http://www.knoxtrans.org/rtap/index.htm, March 2002.
} 
In addition, the solutions must be sustainable. Agreements must be obtained with appropriate jurisdictions, businesses, and agencies in advance.

\subsubsection{Financial}

Operation of a transit system in the GSMNP could benefit financially from use of ITS technologies. Because parking facilities would by necessity be located in or near the gateway communities, which are located in two different states, agreements on shared fares, timetables, and other responsibilities are required. Automatic passenger counters, automatic vehicle location systems, and smart cards are all proven ITS technologies.

For example, between 1996 and 1999, a demonstration project in Ventura County, California, tested smart card technology among seven different transit systems. When using the prepaid pass, passengers could transfer between systems at no extra charge. Lessons learned from this demonstration project could be useful for a potential comprehensive transit system for the Smokies. ${ }^{78}$

\subsubsection{Data and Information}

The data and information needs listed in Section 6.1.5 are being completed through various studies that have recently been completed or are currently underway or are planned for the near future. Obviously, additional information needs may be identified when specific options for specific areas within the Parks have been more clearly identified.

\subsubsection{Technology}

Gatlinburg and Pigeon Forge currently operate trolley bus systems for both residents and tourists independently (Section 4.1). The governments of these two communities traditionally provide services to their residents independently. Advanced public transit technologies such as electronic payment systems could be applied to the transit systems currently operating in the surrounding gateway communities. By using certain type of electronic payment systems, these two governments could continue to operate independently; however, passengers could transfer from one system to the other. To the transit passengers, it would appear to be a single system.

For the highly congested Cades Cove area, because of the flat terrain, small electric buses might be good to transport passengers at moderate speed. Use of electric buses would also improve air quality. In addition, the limited number of parking spaces on the Cades Cove loop road prevents visitors from being able to leave their vehicles to hike, visit historic structures, view wildlife, or take photographs. If the bus service were scheduled in such a way to meet rider demand for exiting and reentering transit vehicles at appropriate points of interest, then there would be greater likelihood of Cove visitors using the transit system.

Traveler information systems depend on knowing a vehicle's location at a point in time. If satellite

\footnotetext{
${ }^{78}$ Federal Highway Administration and Federal Transit Administration, U.S. Department of Transportation, Ventura County Fare Integration: A Case Study, FHWA-OP-01-033; FTA-TRI-11-01-01, September 2001.
} 
"blind" spots could be eliminated, then these systems could provide arrival and departure information at various locations and junctures. In addition, a multi-media presentation within the vehicle could provide additional information on particular features as the vehicle passed nearby.

\subsubsection{Policy}

Recent and current public meetings have been conducive to establishing a strong public support for development of alternative transportation options. Although mass transit is not the top choice of the public attending these meetings, public input into final decisions will be critical for ensuring success.

\subsubsection{Population}

As population grows and transit options shrink, congestion on the highways becomes more common. This is especially evident during the peak tourist months of summer in the Park's gateway communities. Because of the popularity of certain sites in the Park (e.g., Cades Cove), a mass transit system from the gateway communities into/through the Park could provide immense benefits by providing more convenient, safer access for tourists to these popular Park sites.

\subsection{Strategies}

Many agencies and organizations with interest in the GSMNP were noted in Section 5. Their special interests are very diverse, and coordination with and among these agencies will not be simple. Coordination is, however, crucial. In Section 6.1, the challenges and barriers to determining a transportation solution for the Smokies are discussed. In Section 6.2, ITS applications for addressing these issues are discussed.

In the Transportation Technology Assessment for Cades Cove, the review criteria for an alternative transportation technology included the following important considerations:

- Visitor experience (e.g., reliability, comfort, view, convenience);

- Ability to meet visitor demand (e.g., capacity, flexibility, adaptability);

- Resource issues (e.g., environmental and cultural impacts);

- Operational issues (e.g., vehicle design);

- Infrastructure requirements (e.g., vehicles, track, maintenance facilities, parking requirements);

- Cost estimates (e.g., capital and operating).

All of these review criteria are important. In addition, the economic well being of the other gateway communities and the environmental issues of the entire Southern Appalachian Mountain chain must be considered when evaluating alternative transportation systems for the remainder of the Park.

The Cades Cove transportation issue is of critical importance. No other single spot in the Smokies has a problem of such magnitude. Indeed the congestion and safety issues in Cades Cove and its closest gateway city of Townsend, Tennessee, will almost certainly be addressed whether or not 
the general transportation issues of the GSMNP, the air quality issues in the Southern Appalachian Mountains, and/or the economic issues concerning the other gateway communities are addressed.

The gateway communities of Sevierville-Pigeon Forge-Gatlinburg are experiencing severe seasonal congestion. Because all three communities are along the same route into the Park, a solution to the congestion should consider all three communities. In addition, there is increasing traffic along TN-66 between Interstate 40 and Sevierville. (A new Tennessee Smokies baseball park, with a large parking area, is located at TN-66 and Interstate 40.) This corridor is also an important area to address.

A comprehensive strategy would be to develop a long-term plan in coordination with the planning for Cades Cove and the Sevier County corridor. This approach would allow the recommended solutions for the Cades Cove dilemma and the Sevier County corridor to proceed as necessary to alleviate those critical transportation problems and, at the same time, provide a coordinated action plan to resolve the remaining transportation and environmental problems. This strategy would involve examining origin-destination routes at primary Park entrances, determining the best fit of technologies for each potential route, and addressing each of the challenges and barriers noted in Section 6.1.

Additional transportation routes that should be considered for potential alternative transportation options include the following:

Route 1: The route to/from the Sevierville-Pigeon Forge-Gatlinburg-Pittman Center entrance to/from Cades Cove (or to/from the Townsend entrance or some connecting point); Route 2: The route to/from the Sevierville-Pigeon Forge-Gatlinburg entrance up the mountain along U.S. 441 to/from Newfound Gap;

Route 3: The route to/from the Cherokee-Maggie Valley-Bryson City entrance up the mountain along U.S. 441 to/from Newfound Gap; and

Route 4: The route to/from the Townsend entrance to/from Newfound Gap (or to/from some connecting point with Route 2).

All of these routes are interconnecting and would also intersect with the Cades Cove alternative transportation option, whatever that turns out to be. Because of the vast differences in the ridership, terrain, and other operational requirements, the transit system chosen for each route would need to be separate but interconnecting.

Other entrances to the Park do not have a sufficient traffic load to warrant transit service. 


\subsection{Timetable}

Planning for the Cades Cove alternative transportation system includes studies and meetings to arrive at the best possible decision. The Detailed Transportation Management Plan for Cades Cove is scheduled for completion in Spring-Summer 2003. In order to ensure that the public and the gateway communities are involved, a schedule has been set up for various public meetings, public service and other media announcements, and workshops. An environmental impact review may be conducted. Public-private consortiums are important, and the Park is planning on partners to help secure funding for implementation of the plan.

Because there are so many groups interested in GSMNP issues, it is critically important for FTA to become involved with the process, to encourage the interest in transit (albeit small), and to demonstrate the advantages of ITS transit options with respect to congestion, air quality, safety, and the visitor experience. 


\section{SUMMARY, CONCLUSIONS, AND RECOMMENDATIONS}

This part of the report summarizes the findings documented in earlier chapters and provides recommendations for a strategy for addressing the transportation issues that exist in the Smokies.

\subsection{Summary}

As shown in Section 2.2, the GSMNP is the most visited National Park, with visitation increasing every year (Figures 2.1 and 2.2). Although visitation in the Smokies represented 23\% of the total visits to all National Parks during CY2000, the Smokies received only 5\% of the FY2001 Federal Park funding (Figures 2.3 and 2.4).

The GSMNP encompasses parts of six counties in two States. There are three major entrances into the Park with nine gateway communities (Table 2.1). The major transportation issues are congestion, environmental degradation and air pollution, safety, and the visitor experience (Section 2.5).

The number of transit providers in the area surrounding the Park is limited, and only one of these transit systems actually provides a limited service to sites within the Park. Detailed studies are needed to determine which ITS technologies could increase the efficiency and safety of these systems and offer users a greater access to information (Sections 3 and 4).

Because the transportation and environmental issues have become so extremely critical in the GSMNP, many agencies, organizations, and other groups have become involved in finding and advocating solutions. Although the end result is to fix the problems, these groups do not always have the same focus. A listing of pertinent groups is provided in Section 5.

As noted in Section 6.1, there are multiple physical challenges to any solution to transportation issues in the Smokies, including steep terrain and narrow mountainous roads, a lack of communication infrastructure or any ITS technologies, and the need to "lie lightly on the land." There are also environmental concerns. In addition, coordination of all the various jurisdictions and stakeholders will be a major issue. There are currently many on-going studies collecting data and information; these studies need to be coordinated. A concentrated technology assessment on the Cades Cove area is scheduled for conclusion in 2003; a similar study of the remaining areas of the Park is needed. Other data and information needs are also needed. A preliminary assessment of potential technologies is needed to get a "short list" of feasible alternatives. A clear statement of policy, from the economic viewpoint of the gateway communities and local technology providers as well as from a functional and technical requirements viewpoint, is necessary. Contracts and other agreements must be established.

\subsection{Conclusions}

There are obvious benefits of using ITS technologies for establishment of a coordinated transit system. If, indeed, as seems likely, different approaches to transit are needed for the different Park entrances, use of ITS technologies will provide a consistent and integrated systems approach. 
The five objectives of this study have been met. The status of transportation needs in the Smokies is provided in Section 2; current transit options in and around the GSMNP are documented in Sections 3 and 4; the interests and activities of various groups with interest in the Smokies are documented in Section 5; technical and institutional barriers are documented in Section 6, as are strategies for addressing these barriers. This chapter provides short-term and long-term recommendations for options to solve the GSMNP transportation problems.

\subsection{Recommendations}

The purpose of this strategic plan is to provide recommendations for addressing the transportation issues in the GSMNP. Two approaches are recommended - coordination and demonstration.

\subsubsection{Coordination}

This recommendation is for FTA to become involved with and encourage the continuation of the planning processes for the Cades Cove area and the Sevierville-Pigeon Forge-Gatlinburg corridor. In concert with this support, an integrated, comprehensive study of the entire GSMNP, particularly for the entrances at Gatlinburg and Cherokee, needs to be initiated. Four potential interconnecting transit "routes" are described in Section 6.3.

It is also recommended that the available transit and paratransit services in the areas surrounding the GSMNP be coordinated; because of the dual-State, multi-jurisdiction of the agencies supplying these services currently, this coordination will be limited to those functions that improve transit and paratransit service. As indicated in the report, tremendous opportunities exist to improve transportation services in the GSMNP using ITS technologies. Because several studies concerning transportation options have been initiated recently, the time is critical for incorporating ITS technologies into the planning process.

It is also recommended, therefore, that more effort be made, perhaps through the continuation of this project, to participate more actively in the ongoing brainstorming discussion process. It is also recommended that potential partners receive information on the ITS peer-to-peer program and on the deployment of ITS technologies in other National Parks and rural areas.

In summary, the recommendations listed above are for FTA, in coordination with appropriate partners, to:

- Become an integral partner in the current efforts to relieve transportation problems in Cades Cove and the Sevierville-Pigeon Forge-Gatlinburg corridor, encouraging the use of ITS technologies in the final solution; inform the working groups about ITS programs and opportunities;

- Initiate a comprehensive study of the transportation options for the entire GSMNP, integrating the problems of the gateway communities and considering the results of current planning efforts;

- Examine the possible coordination of existing transit and paratransit services in the areas surrounding the Park to enhance these services and possibly extend their service into the Park. Use existing ITS off-the-shelf programs for sharing resources. 


\subsubsection{Demonstration}

Because the greatest need for transit service within the Park is in Cades Cove, this area is an obvious selection for showcasing rural ITS transit capabilities. A successful demonstration of ITS in the Cades Cove area would serve to induce transit in other areas of the Smokies and other congested National Parks. ITS technologies that could effectively be featured in the transit design would include:

- Fleet management software,

- Automatic vehicle location (AVL) software,

- Automatic passenger counters,

- Multimedia display within the vehicle,

- Multimedia displays and automated notifications of expected schedules at the boarding locations.

These technologies would enhance the rider experience by providing an educational experience, need-based scheduling, expected arrival/departure times, and rapid emergency response, if needed. In addition, the passenger counts could be used to determine how transit operation is helping to address congestion and air quality problems. The AVL software, which determines location, could trigger additional information about specific features as the vehicle passes by or announcements of upcoming stops. The multimedia presentation within the transit vehicle could be used to provide a historical, cultural, and ecological tutorial of the area. There is such a wealth of information (e.g., the Heartland series has been extremely successful), that the presentation within the transit vehicle could be changed periodically.

Because some local opposition to a mass transit system exists, a creative approach is needed to overcome the reluctance to ride. It should be noted that there is currently no entrance fee charged for the Smokies; some opposition has been expressed to paying a transit fee. Therefore, the fee structure must be carefully examined to ensure that this concern is addressed. In addition, many local families trace their ancestry back to Cove residents; these persons do not want to be constrained to using mass transit to visit family graves. Therefore, use of the private car should remain an option, especially during non-tourist seasons, when transit would be available less frequently.

Finally, for the multi-media educational experience, advanced technology could be used to enhance the presentation. For example, a free-standing hologram could used to make the presentation more exciting. Different characters (e.g., Cherokee Indian, early settler) could explain the historical features of the landscape. The hologram's remarks could be cued for particular locations based on GPS or roadside sensors.

Other features of the Cades Cove transit system could include:

- Alternative fueled vehicles,

- Accommodations for the transportation disadvantaged,

- Options for transporting bicycles, camping gear, and pets,

- Safe and secure parking areas. 
Alternative fueled vehicles would definitely provide a benefit to air quality issues, if individuals could be persuaded to leave their private vehicles to ride the transit system. Input from the public meetings currently being conducted could be used to determine what transit features would be most desirable.

Another demonstration project that is highly recommended is a Bus Rapid Transit (BRT) application for the Sevierville-Pigeon Forge-Gatlinburg link. This corridor can become highly congested during peak use periods - that is, tourist seasons. Most shoppers would be grateful to go between the shopping Mecas without needing to search for multiple parking slots. This transit demonstration would showcase integrated parking and efficiency. It would be similar to running a train, but less expensive to provide initially. Therefore, it could provide real-life data on numbers of persons who would be willing to take alternative transportation between the cities of Sevierville, Pigeon Forge, and Gatlinburg. There are no examples of BRT in the Tennessee area, and this demonstration could be very valuable from the perspective of introducing new technology in a heavily traveled corridor.

In summary, the demonstration projects recommended above are as follows:

- Advanced ITS technologies applied to a rural transit system for the Townsend to Cades Cove route and the Cades Cove loop road, using alternative-fueled vehicles, operating primarily during the congested tourist season, and

- Advanced ITS technologies applied to a BRT for the Sevierville-Pigeon Forge-Gatlinburg corridor leading to the Gatlinburg entrance to the GSMNP. 


\section{REFERENCES}

American Park Network, Great Smoky Mountains National Park, $9^{\text {th }}$ Ed., 2000.

Appalachian Trail Maintainer Committee, Smoky Mountain Hiking Club, "Appalachian Trail Maintainer News, 2001," http://www.esper.com/smhc/atnews.htm .

Blue Ridge Trail Riders, “About Us,” http://blueridgetrailriders.com.

Cades Cove Technology Assessment Report, produced for the Regional Transportation Alternatives Committee, Knoxville, Tennessee, http://www.knoxtrans.org/rtap/cadescovereport.htm, August 2001.

"Cades Cove Opportunities Plan: Looking Back - Moving Forward," http://www.cadescoveopp.com/ .

Canary Coalition, “The Canary Coalition, a Grassroots Clean Air Movement," http://www.canarycoalition.org .

Cherokee Indian Reservation, http://www.Cherokee-nc.com/main.htm .

Chin, S. M., "Foothills Parkway Traffic Study," Prepared for the Denver Service Center, National Park Service, U.S. Department of the Interior, December 1996.

Department of Energy, "Department of Energy Awards Alternative Fuel Grants to 32 National Parks," http://www.energy.gov/HQPress/releases99/decpr/pr99319.htm .

Department of Interior, Strategic Plan, FY2000-FY2005, http://www.doi.gov/grpa/doi.pdf .

Electric Transit Vehicle Institute, Traffic Congestion and Pollution Reduction Assessment of the Great Smoky Mountains National Park and the Gateway Cities of Sevierville, Pigeon Forge and Gatlinburg, prepared for the Tennessee Department of Transportation, ND.

Electric Transit Vehicle Institute, "Welcome to ETVI," http://www.etvi.org/ and associated links.

Environmental Protection Agency, "Visibility Impairment," http://www.epa.gov/oar/vis/grsm_p.html .

"Experience Your America: Welcome to the Home of the National Park Foundation," http://www.NationalParks.org/index.html .

Farrar-Nagy, Sara, Personal email conversation with Tykey Truett, September 27, 2002.

Federal Highway Administration, ITS Deployment Guidance for Transit Systems Executive Edition, April 1997. 
Federal Highway Administration and Federal Transit Administration, Automatic Vehicle Location Successful Transit Applications: A Cross-Cutting Study, FHWA-OP-99-022; FTA-TRI-11-99-12, August 2000.

Federal Highway Administration and Federal Transit Administration, Federal Lands Alternative Transportation Systems Study: Volume 3: Summary of National ATS Needs, August 2001, http://www.fta.dot.gov/library/policy/fedland/v3/index.html and associated links.

Federal Highway Administration and Federal Transit Administration, Federal Lands Alternative Transportation Systems (ATS) Study: Program Development, August 2001, http://www.fta.dot.gov/library/policy/fedland/v4/exsuml.pdf .

Federal Highway Administration and Federal Transit Administration, Communications for Intelligent Transportation Systems: Successful Practices, FHWA-JPO-99-023; FTA-TRI11-00-02, November 2000.

Federal Highway Administration and Federal Transit Administration, Ventura County Fare Integration: A Case Study, FHWA-OP-01-033; FTA-TRI-11-01-01, September 2001.

Federal Highway Administration and Federal Transit Administration, How Do I Manage and Staff for Intelligent Transportation Systems? Thinking Outside of the Box: A CrossCutting Study, FHWA-OP-99-024; FTA-TRI-11-99-13, August 2000.

Federal Transit Administration, Advanced Public Transportation Systems: The State of the Art, Update 2000, FTA-MA-26-7007-00-1, December 2000.

Federal Transit Administration, U.S. Department of Transportation, Transit Research \& Technology 5-Year-Plan, October 1999.

Fraser, Thomas, "Trying to Bridge the Gap,” The Daily Times, January 31, 2000.

Friends of Great Smoky Mountains National Park, "Friends of the Smokies," http://www.friendsofthesmokies.org.

Goldberg, Andrew, "Mountain Air Quality Coalition,” http://www.wnct.org/maqc1.html .

Knoxville Regional Transportation Planning Organization, Regional Transportation Alternatives Reports (various), http://www.knoxtrans.org, various dates.

Land-of-Sky Regional Council, “Transportation,” http://www.landofsky.org/transportation/ .

Mansfield, Duncan (Associated Press), "Visitor Traffic Accelerates in Smokies," The Daily Times, February 7, 2000.

Moore, Reuben, Personal Communication with Tykey Truett, May 13, 2002. 
"National Parks to Get Energy Efficient Uplift," June 29, 2000, http://www.energy.gov/HQPress/releases00/junpr/pr00176.htm .

National Parks Conservation Association, “About NPCA," http://www.npca.org/about npca/ .

National Parks Conservation Association, "Protect the Smokies - Stop the North Shore Road," http://www.npca.org/take_action/action_alerts/ActionAlert.asp?strAction=link\&lngAlertID=65 .

National Park Service, "Alternative Transportation in the National Parks, Memorandum of Understanding between Secretary of Transportation and Secretary of the Interior," http://www.nps.gov/transportation/alt/mou.htm.

National Park Service, Transportation Planning Guidebook, prepared by Parsons Brinckerhoff Quade \& Douglas, Inc., September 1999.

National Park Service, "Great Smoky Mountains National Park," http://www.nps.gov/grsm/ and associated links.

National Park Service, Budget Justifications and Annual Performance Plan (Greenbook), http://www.nps.gov/budget.

National Park Service, "List of High Ozone in Park Units - 2001 Season," http://www2.nature.nps.gov/ard/gas/exceed.htm\#priorexceeds .

National Park Service, Public Use Statistics Office, http://www2.nature.nps.gov/stats/ .

National Park Service, Great Smoky Mountains National Park, Facts/Docs, "Briefing Statement: Cades Cover Transportation Plan," http://www.nps.gov/grsm/pphtm/facts.html .

National Trust for Historic Preservation, "About the National Trust," http://www.nthp.org/about the trust/index.html?cat=6 .

National Trust for Historic Preservation, "State and Local Partnerships," http://nthp.org/state and local/activities/2002/tennessee.html .

Nine Counties/One Vision, "Transportation Goals \& Strategies," http://www.ninecountiesonevision.org/html/transportation.html .

North Carolina Smartlink, North Carolina Statewise Intelligent Transportation System Strategic Deployment Plan: Western Regional Plan, http://www.ncsmartlink.org/strategic/default.htm.

Palazzolo, Chiara, Personal phone conversation with Tykey Truett, September 25, 2002.

Parsons Brinckerhoff Quade \& Doublas, Inc. Inventory and Assessment of National Park Visitor Transportation Systems, Final Report, August 1999. 
Richardson, Bill, "Green Energy,” pp. 39-40 in National Parks, January/February 2000.

"National Parks to Get Energy Efficient Uplift," June 29, 2000, http://www.energy.gov/HQPress/releases00/junpr/pr00176.htm .

Simmons, Morgan, "Smokies Smoggier than New York," Knoxville News Sentinel, September 24, 2002.

"Smokies Partners with TVA: Experiments with Electric Vehicles," December 5, 2001, http://www.nps.gov/grsm/gsmsite/newselectricvehicles.html .

Smoky Mountains Hiking Club, "Wilderness Advocacy and the Smoky Mountains Hiking Club," http://www.esper.com/smhc/wa/index.htm and associated links.

Southern Appalachian Mountains Initiative, "SAMI," http://www.saminet.org/ and associated links. [This website available through December 2002; thereafter, all SAMI results and studies will be available at http://www.vistas-sesarm.org .

Southern Appalachian Mountains Initiative, SAMI: Southern Appalachian Mountains Initiative Final Report, August 2002.

"State Official Says Parking Lot in Townsend Will Be Built," The Daily Times, April 17, 2002.

"Supporters of Smokies Converge in Townsend," The Daily Times, April 19, 2002.

Tennessee Department of Transportation, Intelligent Transportation Systems Strategic Plan, Annual Report, August 2000.

Tennessee Department of Transportation, Intelligent Transportation Systems Strategic Plan, Annual Report, November 2001, http://www.tdot.state.tn.us/chief_of_administration/Strategic_planning_office/itsplan.pdf .

Tennessee Department of Transportation, TDOT Strategic Plan, March 2000, http://www.tdot.state.tn.us/chief_of_administration/Strategic_planning_office/2000_Strat egic_Plan/strategic_plan.htm.

Tennessee Department of Transportation, 2002-2003 TDOT Strategic Plan, March 2002, http://www.tdot.state.tn.us/chief_of_administration/Strategic_planning_office/2002_Strat egic Plan/strategic plan.htm.

Tennessee Department of Transportation, Hybrid-Electric Bus Charges Winter Light Festival, TDOT Electric Bus Demonstration project Newsletter, Issue 3, January 1999.

Tennessee Department of Transportation, A Breath of Fresh Air Visits Pigeon Forge, TDOT Electric Bus Demonstration project Newsletter, Issue 1, October 1998. 
"The National Park Foundation and Ford Motor Company Support Transportation Study in Smokies," KnoxNews, April 17, 2002,

http://www.knoxnews.com/kns/inside the park/article/0,1406,KNS 391 1089046,00.html.

TransCore, Rural Public Transportation Technologies: User Needs And Applications - Final Report, July 1998.

Transportation Research Board, National Research Council, New Paradigms for Local Public

Transportation Organizations, TCRP Report 58, National Academy Press, Washington, D.C., 2000.

Transportation Research Board, National Research Council, Management Toolkit for Rural and Small Urban Transportation Systems, TCRP Report 54, National Academy Press, Washington, D.C., 1999.

Turnbull, Katherine F., "Visitor Transportation at U.S. National Parks: Increasing Accessibility but Preserving the Environment," pp. 3-8 in TR News, No. 210, September-October 2000.

U.S. Census Bureau, Census 2000 Gateway, http://www.census.gov/main/www/cen2000.html .

Valentine, Clinton, Personal e-mail conversation with Tykey Truett, May 2, 2001.

Volpe National Transportation Systems Center, Advanced Public Transportation Systems: The State of the Art Update 2000, December 2000.

Western North Carolina Tomorrow, “The Voice of the Mountain Region,” http://wnct.org .

Wilbur Smith Associates, "Regional Transportation Alternatives Plan for East Tennessee," prepared for Knoxville Urban Area Metropolitan Planning Organization, May 2000.

Wilbur Smith Associates, Regional Transportation Alternatives Plan (RTAP) for East Tennessee, Final Report, prepared for Mr. Jeff Welch, Knoxville Regional Transportation Planning Organization, Knoxville, Tennessee, March 2002. 


\section{APPENDIX A \\ MAPS}

The following maps provide the information necessary to understand the difficulties of providing transit options within the Great Smoky Mountains National Park.

Figure Title

A.1 The Great Smoky Mountains National Park and Surrounding Area

A.2 Tennessee and North Carolina Counties That Contain Portions of the Great Smoky Mountains National Park

A.3 Points of Interest within the Great Smoky Mountains National Park

A.4 Topographic Representation of the Mountain Ranges within the Smokies

A.5 View of U.S. Highway 441 across the Mountains between Gatlinburg, Tennessee, and Cherokee, North Carolina 


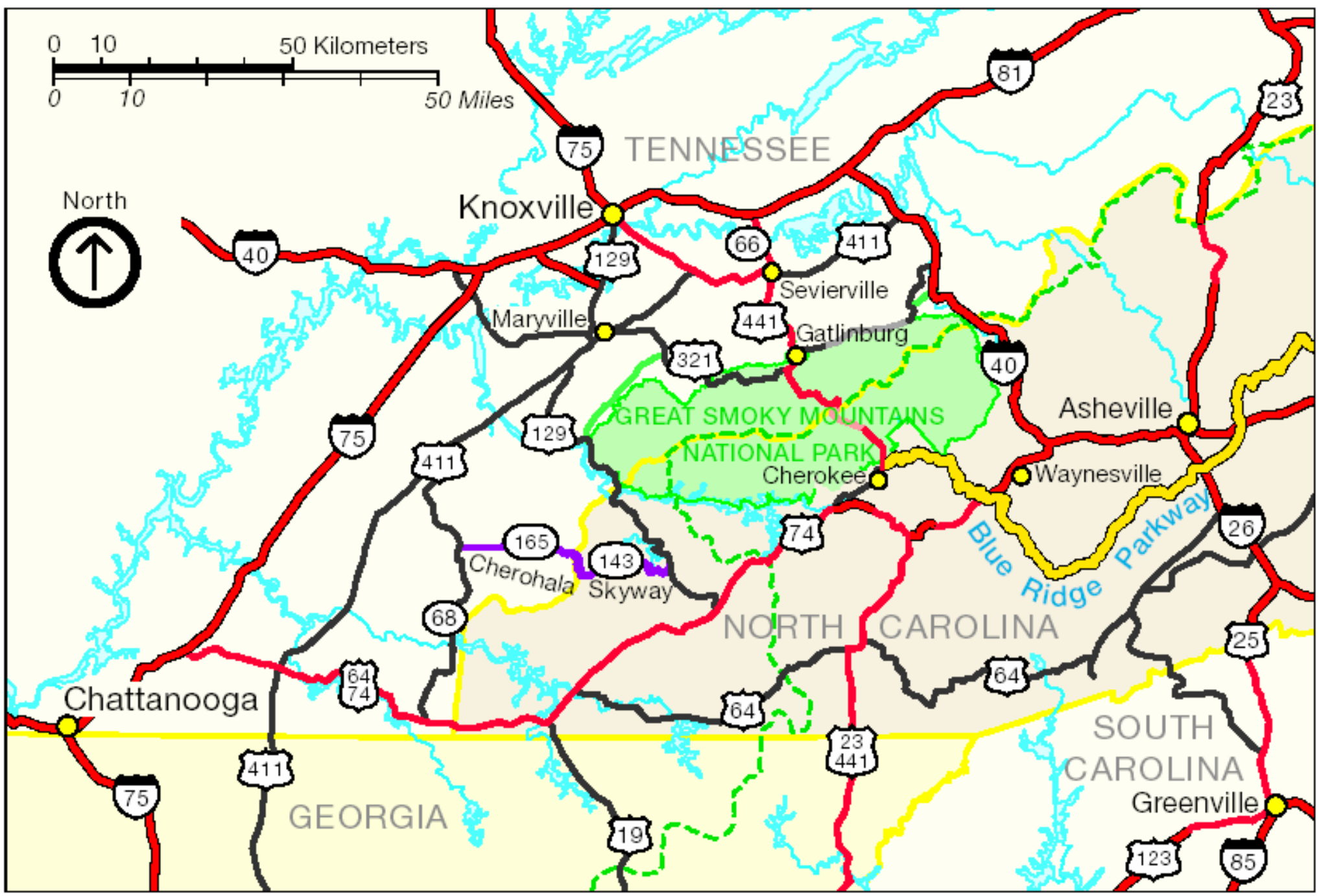

Figure A.1. The Great Smoky Mountains National Park and Surrounding Area. Source: National Park Service, “Great Smoky Mountains National Park," www.nps.gov/grsm/pphtml/maps.html . 


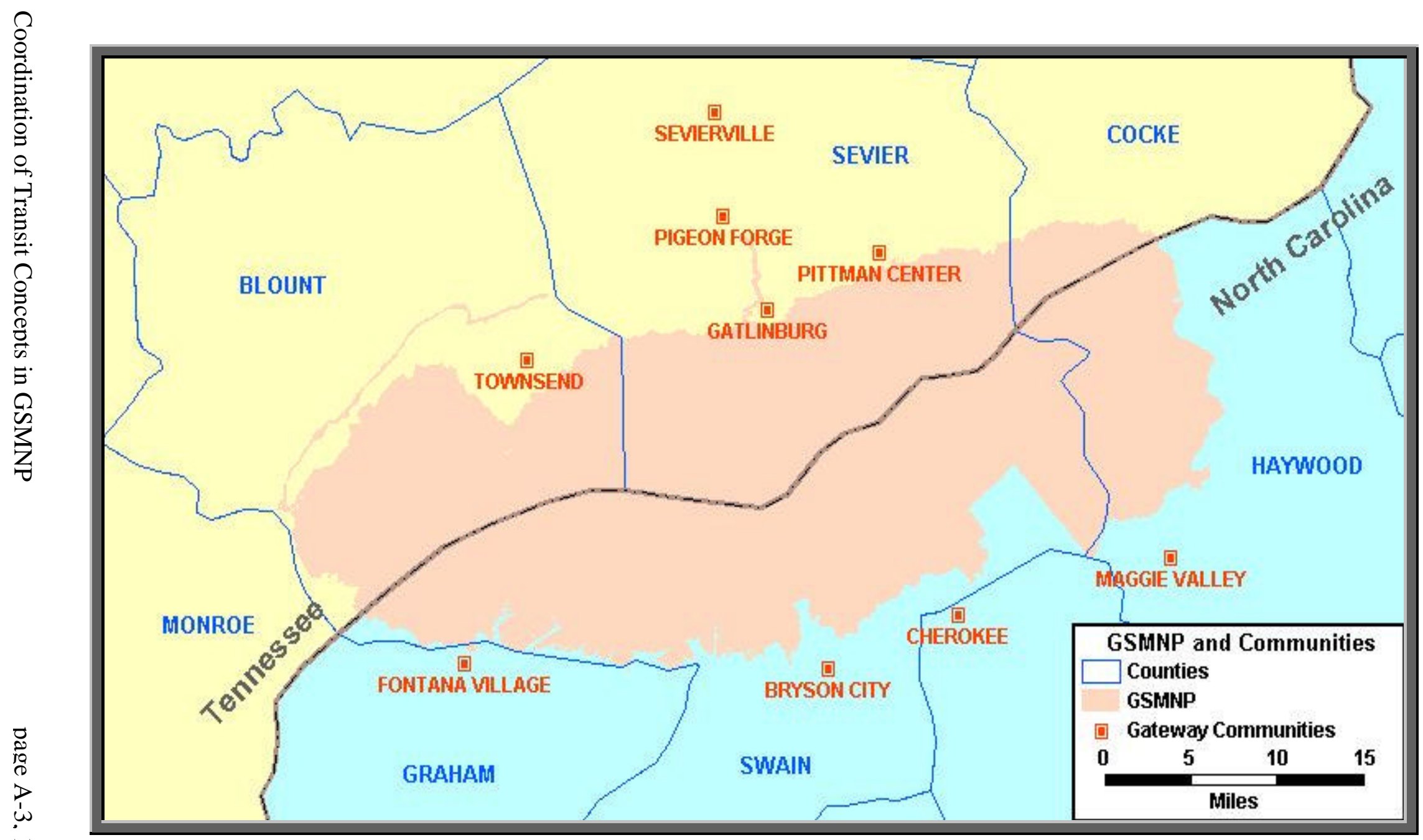

Figure A.2. Tennessee and North Carolina Counties That Contain Portions of the Great Smoky Mountains National Park. 


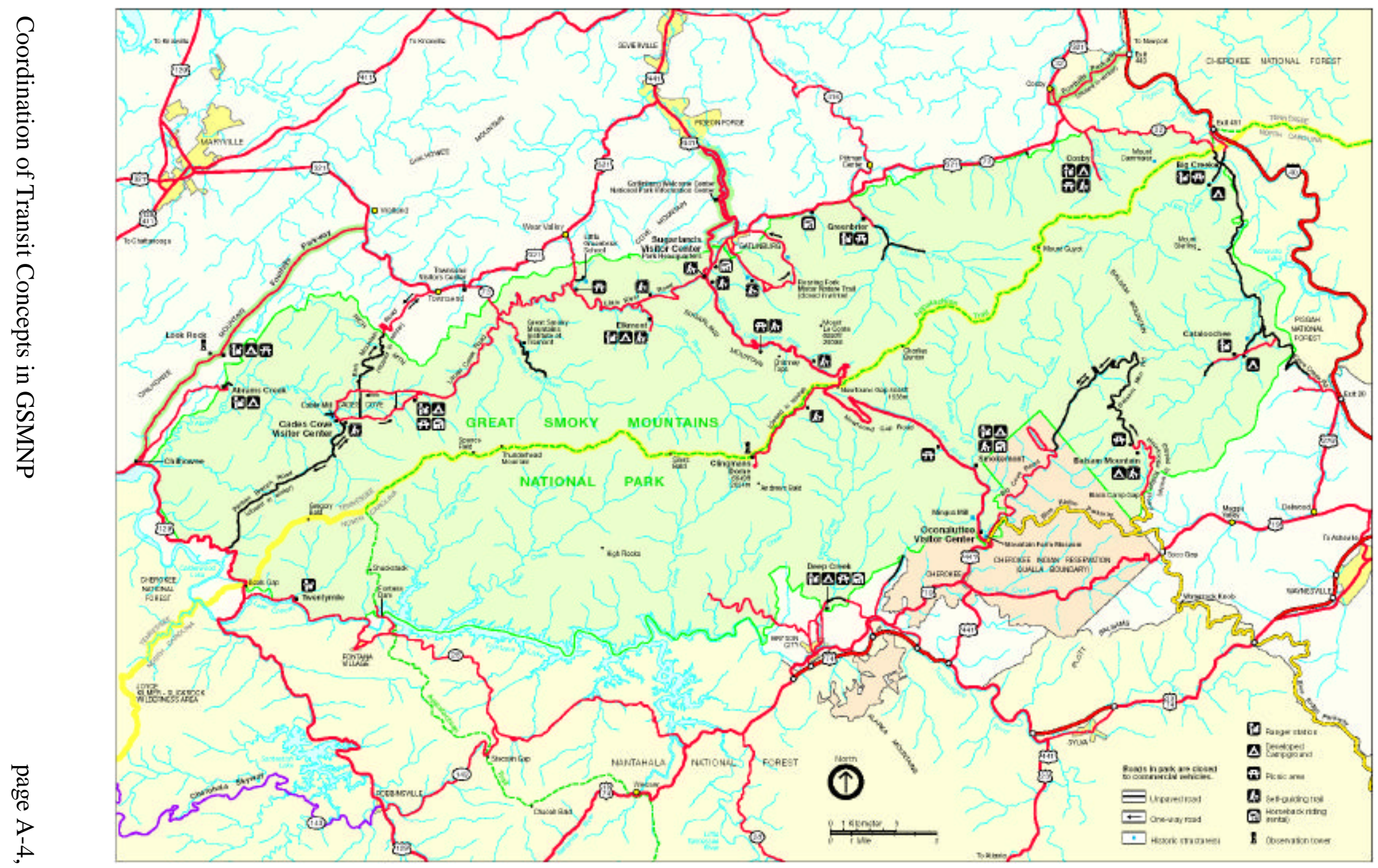

Figure A.3. Points of Interest within the Great Smoky Mountains National Park. Source: National Park Service, “Great Smoky Mountains National Park," www.nps.gov/grsm/pphtml/maps.html. 


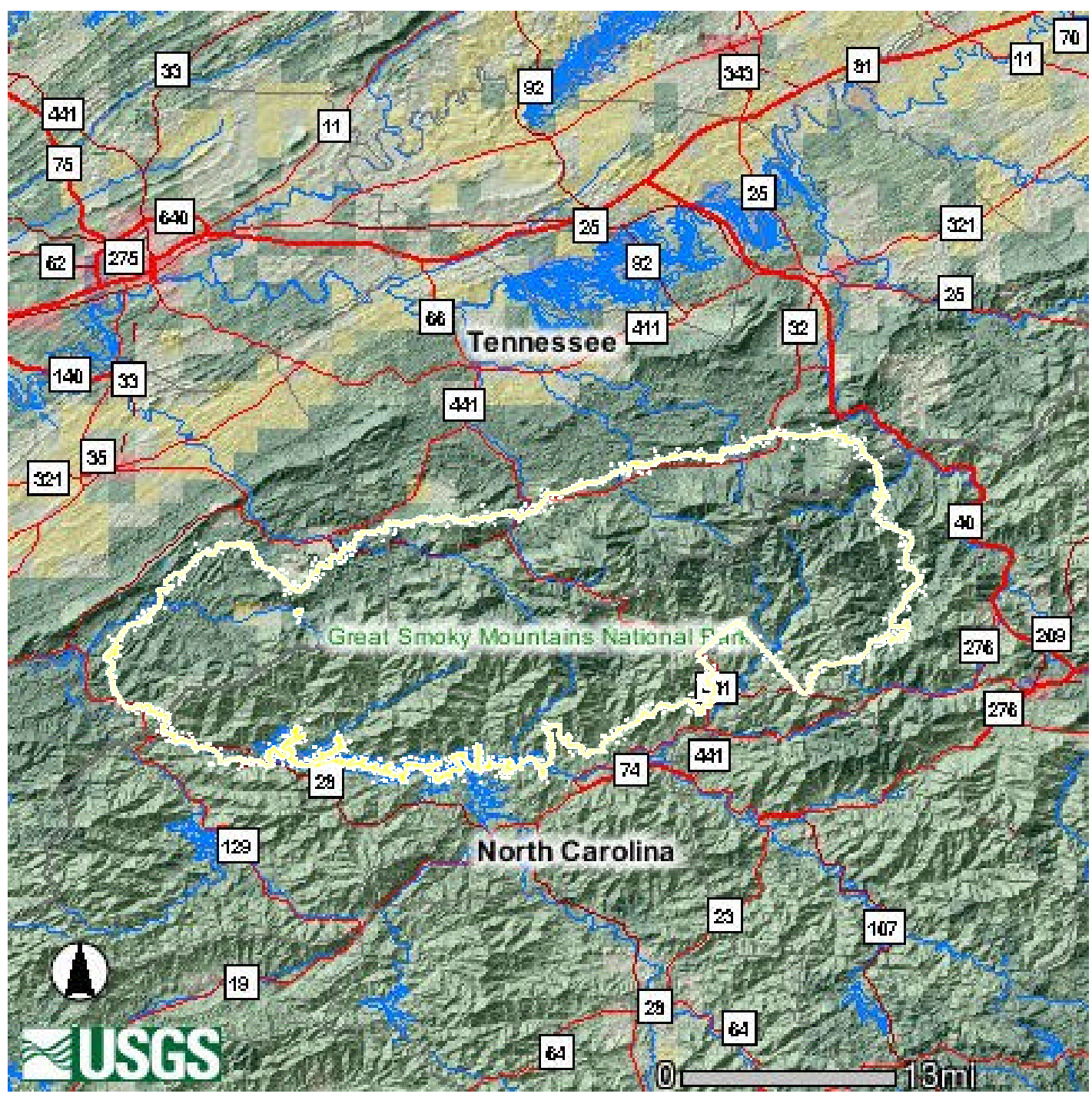

Figure A.4. Topographic Representation of the Mountain Ranges Within the Smokies. Along the border between Tennessee and North Carolina, the elevation levels range from about 3,780 feet to about 6,600 feet mean sea level. 


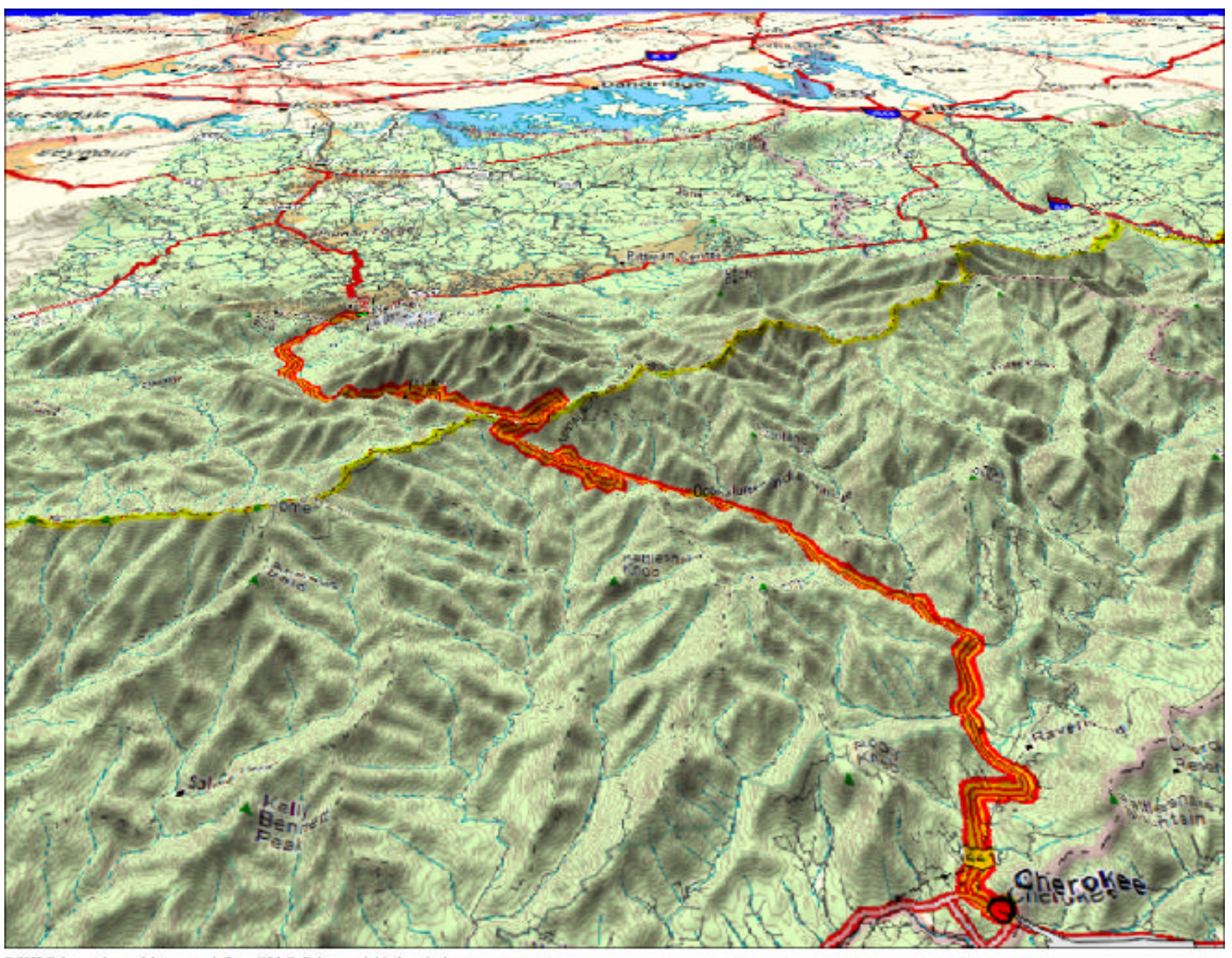

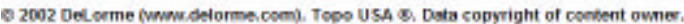

Figure A.5. View of U.S. Highway 441 across the Mountains Between Gatlinburg, Tennessee, and Cherokee, North Carolina. 


\section{APPENDIX B \\ ACRONYMS AND INITIALISMS}

$\begin{array}{ll}\text { AT } & \text { Appalachian Trail } \\ \text { AVL } & \text { Automatic Vehicle Location } \\ \text { BRT } & \text { Bus Rapid Transit } \\ \text { CY } & \text { Calendar Year } \\ \text { DENR } & \text { Department of Environment and Natural Resources } \\ \text { DOE } & \text { Department of Energy } \\ \text { DOI } & \text { Department of Interior } \\ \text { DOT } & \text { Department of Transportation } \\ \text { EPA } & \text { Environmental Protection Agency } \\ \text { ETHRA } & \text { East Tennessee Human Resource Agency } \\ \text { ETVI } & \text { Electric Transit Vehicle Institute } \\ \text { FHWA } & \text { Federal Highway Admi nistration } \\ \text { FTA } & \text { Federal Transit Administration } \\ \text { FY } & \text { Fiscal Year } \\ \text { GSMNP } & \text { Great Smoky Mountains National Park } \\ \text { ITS } & \text { Intelligent Transportation System } \\ \text { MOU } & \text { Memorandum of Understanding } \\ \text { NCDOT } & \text { North Carolina Department of Transportation } \\ \text { ND } & \text { No Date } \\ \text { NPCA } & \text { National Parks Conservation Association } \\ \text { NPS } & \text { National Park Service } \\ \text { OPT } & \text { Office of Public Transportation } \\ \text { RTAC } & \text { Regional Transportation Alternatives Committee } \\ \text { RTAP } & \text { Regional Transportation Alternatives Plan } \\ \text { SAMI } & \text { Southern Appalachian Mountain Initiative } \\ \text { SMHC } & \text { Smoky Mountains Hiking Club } \\ \text { TDOT } & \text { Tennessee Department of Transportation } \\ \text { TEA-21 } & \text { Transportation Equity Act for the 21 } 1^{\text {st }} \text { Century } \\ \text { TN } & \text { Tennessee } \\ \text { TPO } & \text { Transportation Planning Organization } \\ \text { TRB } & \text { Transportation Research Board } \\ \text { TVA } & \text { Tennessee Valley Authority } \\ & \end{array}$

